\title{
Claroscuros de la reforma de 2006 sobre el mercado de trabajo
}

\author{
Francisco Javier Arrieta Idiakez \\ Profesor de Derecho del Trabajo \\ Universidad de Deusto
}

Recibido: 26.01.07

Aceptado: 15.06.07

\begin{abstract}
Resumen: Este estudio pretende describir los claroscuros que presenta la reforma de 2006 sobre el mercado de trabajo. Para ello, en primer lugar, se contextualiza el diálogo social entre el Gobierno y las organizaciones sindicales y empresariales más representativas a nivel estatal, del que trae causa esta reforma. De esta manera, se reflexiona sobre la evolución y la razón de ser del diálogo social en España. En segundo lugar, se analizan las principales medidas adoptadas en la reforma, y que se instrumentan, primero, por el Real Decreto-ley 5/2006 y, después, por la Ley 43/2006, con el objetivo de fomentar la contratación indefinida, mejorar la utilización de la contratación temporal, mejorar la protección de los trabajadores ante la falta de empleo y potenciar las políticas activas de empleo.

Palabras clave: Reforma de 2006 sobre el mercado de trabajo, diálogo social, legislación negociada, fomento de la contratación indefinida, concatenación de contratos temporales.

Abstract: The present study aims to describe the grey areas the Labour Market's reform has brought along. To this end, the first steps taken, them being the social dialogue that has taken place amongst the Government and both sides of industry, has been put in context. Accordingly, we also find a review of the meaning of Social Dialogue in Spain. From there, we take on to the main measures adopted through the reform, which are taken into effect through the Real Decretoley 5/2006, and the Law 43/2006, aimed at encouraging long term employment, the rationalisation of temporary contracts, protection of workers from the lack of employment opportunities, and to push forward active policies for employment.
\end{abstract}

Key words: 2006 Labour Market reform, Social Dialogue, Negotiated legislation, encouragement of long term employment, short term contract chain.

Sumario: Presentación.-1. Principales características de la reforma: reflejo de las luces y sombras del diálogo social. 1.1. Las experiencias del diálogo social y la reforma laboral de 1997. 1.2. La ruptura del diálogo social. 1.3. La recuperación del diálogo social y la reforma de 2006.2. Medidas adoptadas para fomentar la contratación indefinida.3. Modificaciones introducidas para mejorar la utilización de la contratación temporal. 3.1.La fulminante desaparición del contrato de inserción. 3.2. La supuesta reorientación del contrato para la formación. 3.3. La limitación a la concatenación de contratos temporales. 3.4. Medidas adoptadas para mejorar la transparencia en la subcontratación de obras y ser- 
vicios y su delimitación respecto de la cesión ilegal de trabajadores.4. Medidas adoptadas para mejorar la protección de los trabajadores ante la falta de empleo y para potenciar políticas activas de empleo. 4.1. Las medidas adoptadas respecto al Fondo de Garantía Salarial. 4.2. La mejora de la protección por desempleo de colectivos específicos. 4.3. La mejora de los servicios públicos en el mercado de trabajo.-ANEXO Programa de Fomento de Empleo de la Ley 43/2006.

\section{Presentación}

1. La reforma del mercado de trabajo instrumentada, primero, mediante el Real Decreto-ley 5/2006, de 9 de junio para la Mejora del Crecimiento y del Empleo ${ }^{1}$, y, después, por la Ley 43/2006, de 29 de diciembre $^{2}$, de igual denominación que el real decreto-ley, obedece a la necesidad de superar los dos grandes problemas del mercado de trabajo español: el insuficiente volumen de empleo y el alto nivel de temporalidad.

2. En realidad, estos problemas se circunscriben en el complejo y prolongado fenómeno de la globalización económica.

Fruto de la globalización, la regulación rígida de las relaciones laborales, extendida tras la Segunda Guerra Mundial, dejó paso a la flexibilización exorbitante de la década de los ochenta. Efectivamente, la crisis de mediados de los setenta y la mayor competitividad entre las empresas desembocó, respectivamente, en importantes fenómenos de desindustrialización y en la necesidad de abaratar los costes de producción. De este modo, en el mercado de trabajo acabaron por concurrir una importante tasa de desempleo y un amplio abanico de medidas flexibilizadoras, entre las que destacaban la apuesta por la descentralización productiva, vía contratación y subcontratación, y el aumento inusitado de la contratación temporal.

Asimismo, el legislador no sólo asumió como inevitable la tendencia flexibilizadora, como único cauce posible para mantener la productividad, sino que, además, le dio cobertura, al regular una amplia gama de contratos temporales, como «mal menor» para disminuir el desempleo.

No obstante, la flexibilidad llevada a cabo únicamente con fines productivos, sin tener en cuenta sus efectos para con los trabajadores, se tornó, durante la década de los noventa, en causa de inestabilidad y precariedad, al compás de una rotación en el empleo que daba como resultado la falta de competitividad de las empresas españolas. Además, el mercado de trabajo comenzaba a tener nuevos retos, tales como la incorporación masiva de la

${ }^{1}$ BOE de 14 de junio de 2006, núm. 141.

${ }^{2}$ BOE de 30 de diciembre de 2006, núm. 312. 
mujer, la llegada de numerosos inmigrantes, los problemas de ciertos sectores de la población para acceder a un empleo (jóvenes, discapacitados, desempleados de edad avanzada) y el envejecimiento de la población.

3. En este sentido, el mercado de trabajo español se ha visto abocado a constantes modificaciones, subordinadas siempre a las exigencias de la economía ${ }^{3}$. Sin embargo, a partir de mediados de los noventa, dichas modificaciones también comienzan a estar sujetas, aunque tímidamente, al quehacer que obliga la reminiscencia de la justicia social inspiradora del Derecho del Trabajo $^{4}$. Éste es el contexto en el que debe encuadrarse la reforma de 2006.

\section{Principales características de la reforma: reflejo de las luces y som- bras del diálogo social}

4. Ciertamente, una de las principales virtudes de la reforma consiste en asumir que la solución de los grandes problemas que presenta el mercado de

\footnotetext{
${ }^{3}$ Tal y como indica OrTIz LALlanA, «paradójicamente, el Derecho del Trabajo, inicialmente destinado a la protección de los trabajadores y sus derechos frente al poder empresarial, da paso a un Derecho protector de los niveles de empleo al servicio de la competitividad de las empresas que, llevado de un "realismo intenso" trata de ajustar el Derecho a las transformaciones de la realidad del trabajo y de la economía y a su posible evolución. Este progresivo deslizamiento de sus objetivos trasciende su propia funcionalidad y las finalidades de la disciplina, que decididamente lleva a poner en tela de juicio su propia efectividad». No obstante, tal y como señala dicho autor, debe concluirse que «el futuro del Derecho del Trabajo no está en su "destrucción", sino en su "reconstrucción" o en su "transformación"...» (ORTiz Lallana, C. La supervivencia del Derecho del Trabajo. In AL, 1999, vol. III, pp. 815-816).

${ }^{4}$ Este punto de inflexión se produce tras la reforma del mercado de trabajo de 1994, consistente en un paquete normativo compuesto por cuatro leyes distintas: la Ley 10/1994, de 19 de mayo, de Medidas Urgentes de Fomento de la Ocupación (BOE de 23 de mayo de 1994, núm. 122); la Ley 14/1994, de 1 de junio, por la que se regulan las empresas de trabajo temporal (BOE de 2 de junio de 1994, núm. 131); la Ley 11/1994, de 19 de mayo, por la que se modifican determinados artículos del Estatuto de los Trabajadores, del Texto Articulado de la Ley de Procedimiento Laboral y de la Ley sobre Infracciones y Sanciones en el Orden Social (BOE de 23 de mayo de 1994, núm. 122); y la Ley Orgánica 14/1994, de 19 de mayo, por la que se incluye una Disposición Adicional cuarta a la Ley Orgánica 11/1985, de 2 de agosto, de Libertad Sindical (BOE de 20 de mayo de 1994, núm. 120). Concretamente, los objetivos de dicha reforma se centraban en conseguir la mayor competitividad de las empresas y en crear más empleo. Para ello se realizó una importante reinterpretación de la flexibilidad y se potenció la negociación colectiva. Al respecto, vid. SALA FRANCO, T. La reforma del mercado de trabajo. Valencia: CISS, 1994, pp. 375. Al mismo tiempo son muchos los autores que por esas fechas comienzan a criticar las consecuencias negativas que se derivan de los excesos de una flexibilización mal entendida. Por todos, Monereo Pérez, J. L. Introducción al nuevo Derecho del Trabajo. Una reflexión crítica sobre el Derecho flexible del Trabajo. Valencia: Tirant lo Blanch, 1996, p. 414.
} 
trabajo en España, pasa por mantener un equilibrio entre la flexibilidad en la regulación de las relaciones laborales requerida por los empresarios y la seguridad y estabilidad en el empleo reclamada por los trabajadores 5 . Por lo demás, dicho equilibrio se ajusta al fin último del Derecho del Trabajo.

5. La herramienta elegida para llevar a cabo esta difícil tarea ha sido la concertación social o el diálogo social tripartito entre el Gobierno y las organizaciones sindicales y empresariales más representativas a nivel estatal (CC. OO., UGT, CEOE y CEPYME).

Con ello se vuelve a recuperar una práctica que, a pesar de contar, de una u otra manera, con importantes antecedentes desde comienzos del actual sistema democrático, había languidecido en la legislatura precedente ${ }^{6}$. Más concretamente, se vuelve a la senda del diálogo social iniciado en 1995 que dio lugar a la reforma del mercado de trabajo de $1997^{7}$.

Por todo ello, resulta imprescindible partir de las experiencias de este diálogo social, así como de su crisis durante la anterior legislatura, para poder acercarse a la actual reforma laboral, fruto del diálogo social recuperado.

\subsection{Las experiencias del diálogo social y la reforma laboral de 1997}

6. La reforma del mercado de trabajo de 1997, supuestamente, vino a confirmar la consolidación de los sindicatos y de las asociaciones empresariales en lo que respecta al cumplimiento de las funciones que les son atribuidas por el artículo 7 de la Constitución Española, a saber, «la defensa y promoción de los intereses económicos y sociales que les son propios». Pues, en principio, el diálogo social se llevó a cabo única y exclusivamente a dos bandas, entre los sindicatos y las asociaciones empresariales con mayor representatividad de ámbito estatal (CC.OO., UGT, CEOE y CEPYME).

${ }^{5}$ VV. AA. La Reforma Laboral de 2006. Análisis del Real Decreto-ley 5/2006, de 9 de junio (Sempere Navarro, A.V., Dir.). Cizur Menor: Aranzadi, 2006, p. 15.

${ }^{6}$ Cruz Villalón, J. «La reforma laboral de 2006 en el marco de la concertación social». In VV. AA. La Reforma Laboral de 2006. Real Decreto Ley 5/2006, de 9 de junio (CRUZ Villalón, J., Coord.). Valladolid: Lex Nova, 2006, p. 15. De cara a un análisis pormenorizado de la evolución atinente a la concertación social en el actual sistema democrático, véase Álvarez Cuesta, H. La mayor representatividad sindical. León: Universidad de León, 2006, pp. 115-132. Del mismo modo, se trata la evolución de la concertación social, profundamente, desde los primeros años de la democracia hasta la reforma laboral de 1997, con interesantes puntos de vista en OliET PALÁ, A. La concertación social en la democracia española: crónica de un difícil intercambio. Valencia: Tirant lo Blach, 2004, p. 534.

${ }^{7}$ Puede consultarse abundante bibliografía sobre esta reforma en VALDÉs AlOnso, A. «Bibliografía sobre la reforma laboral de 1997». In Estabilidad en el empleo, Diálogo Social y Negociación Colectiva. La Reforma Laboral de 1997 (RODRÍGUEZ-PiÑERO, M., VALdés Dal-Re, F. y Casas BaAmonde, M. E., Coord.). Madrid: Tecnos, 1998, pp. 322-323. 
Precisamente, fruto del diálogo mantenido, las partes sociales implicadas aprobaron el 28 de abril de 1997 el «Pacto Laboral por el Empleo». En virtud de dicho pacto, en realidad, las partes suscribieron el Acuerdo Interconfederal para la Estabilidad en el Empleo (AIEE), el Acuerdo Interconfederal sobre Negociación Colectiva (AINC) y el Acuerdo Interconfederal sobre Cobertura de Vacíos (AICV). Ahora bien, los diferentes contenidos y objetivos de los acuerdos hicieron que éstos tuviesen desigual importancia en la reforma.

En efecto, el AINC y el AICV se habían constituido material y formalmente a dos bandas, y se insertaban en la normalización de las relaciones entre las partes sociales, con los objetivos de planificar y ordenar el desarrollo de la negociación colectiva, así como de rellenar vacíos de cobertura de ésta. Por su parte, el AIEE, aunque formalmente constituido a dos bandas, contaba con el Gobierno como tercer y principal destinatario, en la medida en que éste había adquirido de antemano el compromiso de aceptar y tramitar las propuestas pactadas por las partes sociales para reformar el mercado de trabajo. De esta forma, se abren las puertas a la legislación negociada y a una nueva fase del Derecho del Trabajo.

7. La legislación negociada, que ha llegado a considerarse como un «fenómeno político-jurídico complejo, propio de los Estados sociales y democráticos de Derecho» ${ }^{8}$, viene a reforzar psicológicamente la autoridad de la ley desde el punto de vista político y sociológico9. Tal es así que mediante la legislación negociada resulta posible mantener la paz social, ya que los propios interlocutores sociales se convierten en compañeros de viaje del Gobierno.

Con VALDÉs DAL-RE, podría decirse que la legislación negociada «constituye el procedimiento normativo de síntesis en el que se funden los dos cauces históricos de juridificación de.... las relaciones sociales; en el que convergen, en suma, soberanía política y autonomía privada $»^{10}$. De esta manera, en sí, cualquier pacto entre las partes sociales que tenga por objeto reformar en su conjunto el mercado de trabajo carece de toda operatividad jurídica si finalmente no es instrumentado por el Gobierno o el parlamento. Con otras palabras, la voluntad de las partes sociales necesita un impulso que trascienda una mera situación de hecho, para convertirse en un verdadero acto jurídico.

\footnotetext{
${ }^{8}$ Borrajo DACruZ, E. «Los nuevos contratos laborales o la magia social de las leyes pactadas». In AL, 1997, vol. II, núm. 26, p. 631.

${ }^{9} \mathrm{Al}$ respecto, Pedrajas Moreno, A. «Novedades en la contratación laboral tras el Real Decreto-ley 8/1997, de 16 de mayo». In RL, 1997, vol. II, pp. 113-115.

${ }^{10}$ VALDÉS DAL-RE, F. «La legislación laboral negociada». In RMTAS, 1997, núm. 3, p. 172.
} 
En definitiva, la legislación negociada nos sitúa ante un nuevo fenómeno de creación normativa. El resultado, bien se trate de un real decreto-ley, bien se trate de una ley, no altera los elementos que actualmente constituyen la jerarquía de fuentes del ordenamiento jurídico laboral. Lo que cambia es la metodología empleada para ello, al superarse la perspectiva clásica referente a la relación vertical entre ley y convenio colectivo, y apostarse ahora por una relación horizontal, que de momento carece de tipificación.

8. Así sucedió con el AIEE, que, pese a su denominación, supera con creces el más amplio contenido posible que puedan llegar a tener los acuerdos interconfederales regulados en el artículo 83.2 del ET. Realmente, el acuerdo adoptado por las partes sociales contaba con la garantía de ser asumido por el Gobierno. De hecho, el Gobierno asumió dicho acuerdo al convertirlo en el Real Decreto-ley 8/1997, de 16 de mayo, de medidas urgentes para la mejora del trabajo y el fomento de la contratación indefinida ${ }^{11}$.

Además, con esta forma de proceder se dio un salto cualitativo respecto a la concertación social a tres bandas de los años ochenta. Aquélla no sólo no pasó a cobijarse bajo la moderna dicción de diálogo social, por influencia de la terminología supranacional, sino que también salió revalorizada, por la importancia que comenzaban a tener las partes sociales. Por otro lado, si bien el nuevo período de diálogo social, al igual que sucediese con la concertación social de antaño, venía a reflejar un cierto neocorporativismo a la hora de afrontar los problemas que presentaba el mercado de trabajo, el fenómeno de la legislación negociada permitió introducir importantes matizaciones.

En consecuencia, con el diálogo social que se materializa en la reforma de 1997, el neocorporativismo adquiere una nueva dimensión. Efectivamente, las partes sociales pierden el carácter de subordinación que presentaban en la década de los ochenta respecto al Gobierno, y adquieren el grado de autonomía suficiente, necesario para participar o cooperar como poder legítimo en la elaboración de las normas ${ }^{12}$.

${ }^{11}$ BOE de 17 de mayo de 1997, núm. 118.

${ }^{12}$ En verdad, los acuerdos de la década de los ochenta, fruto de la concertación social a tres bandas, carecían de eficacia jurídica, y su cumplimiento dependía única y exclusivamente de la actuación del Gobierno. Ejemplos de esta concertación social a tres bandas fueron el Acuerdo Nacional del Empleo (ANE) firmado el 9 de junio de 1981 por el Gobierno, la CEOE, UGT y CC. OO. y el Acuerdo Económico y Social (AES) suscrito el 9 de octubre de 1984 (BOE de 10 y 12 de octubre de 1984, núms. 243 y 245) por el Gobierno, la CEOE, CEPYME y UGT. Sobre estos acuerdos, en general, puede consultarse LANDA ZAPIRAIN, J. P. «Concertación social y sindicatos en España: un balance provisional». In RT, 1987, vol. II, núm. 86, pp. 133-142. En concreto, en torno al AES, véase BAYLOS GRAU, A. «La intrincada frondosidad de los acuerdos tripartitos. Notas sobre la naturaleza jurídica del AES». In Revista Jurídica Española La Ley, 1985, vol. I, pp. 1166-1174. Igualmente, para comprender la naturaleza del AES, véase PALOMEQue LóPEZ, M. C. y CASAS BAAMONDE, M. E. «Participación de sindicatos representativos, no firmantes del AES, en las Comisiones establecidas por el Acuerdo». In RL, 1985, núm. 4, pp. 348-370. 
9. En este contexto, el clima de diálogo social que rodeó la reforma de 1997 supuso un giro copernicano en la postura de los sindicatos con mayor representatividad a nivel estatal. Aquellos mismos sujetos que se habían opuesto radicalmente a la reforma laboral de 1994, llamando a la huelga general en su contra, aceptaban en 1997 seguir la línea de los propósitos declarados ya en 1994, a saber, menos precariedad y despidos más flexibles $^{13}$.

En realidad, los cambios respecto a la reforma de 1994 fueron puntuales, en la medida en que tan sólo se corrigieron algunos aspectos concretos, principalmente, en materia de contratación y de despido. Al fin y a la postre, se trataba más bien de ahondar en la reforma de 1994, de completarla, de consolidarla ${ }^{14}$. Bajo la premisa de aceptar el equilibrio que debe existir entre flexibilidad y estabilidad en el empleo, se pretendía luchar conjuntamente contra los graves problemas del paro, la precariedad y la alta rotación del empleo.

Para ello, los instrumentos elegidos consistieron, básicamente, en «potenciar la contratación indefinida; favorecer la inserción laboral y la formación teórico-práctica de los jóvenes; especificar y delimitar los supuestos de utilización de la contratación laboral, especialmente los contratos de obra o servicio o eventual por circunstancia de la producción, y mejorar el... marco de la protección social del trabajo a tiempo parcial...» (apartado II, de la Exposición de Motivos del Real Decreto-ley 8/1997).

Pero, entre todos los instrumentos, la medida estrella de la reforma de 1997, tanto por su carácter novedoso, como por su alcance, fue la regulación del llamado contrato para el fomento de la contratación indefinida. Con esta medida, en la lucha contra el desempleo, de un lado, se incentivaba por vez primera la contratación indefinida, con el objetivo de contrarrestar los efectos perversos derivados de la hasta entonces excesivamente incentivada contratación temporal. De otro lado, este nueva modalidad contractual presentaba la peculiaridad de abaratar los despidos objetivos declarados improcedentes, con el doble objetivo de introducir un mayor grado de flexibilidad en el empleo y, a partir de dicha flexibilidad, atraer el interés de los empresarios hacia la contratación indefinida, alejándolos de la cultura de la temporalidad.

10. La gravedad de los problemas a los que debía enfrentarse con urgencia el mercado de trabajo, en pro de la competitividad de las empresas nacio-

${ }^{13}$ Rodríguez-PiÑero, M. «El Acuerdo Interconfederal para la Estabilidad del Empleo y la nueva reforma del mercado de trabajo». In Estabilidad en el empleo, Diálogo Social y Negociación Colectiva. La Reforma Laboral de 1997 (RoDRíGUEZ-PIÑERO, M., VALDÉs DALRe, F. y Casas BaAmonde, M. E., Coord.). Madrid: Tecnos, 1998, p. 23.

${ }^{14}$ RodRíGUEZ-PIÑERO, M. «La reforma legislativa anunciada y el Acuerdo Interconfederal para la Estabilidad del Empleo». In RL, 1997, vol. I, pp. 72-73. 
nales, que sólo podía sostenerse articulando en sus justos términos flexibilidad y estabilidad en el empleo, justificó el encauzamiento de la reforma vía real decreto-ley. No en vano, el AIEE ya había declarado formalmente el grave deterioro del empleo en España, en un momento de cambio en las estructuras económicas mundiales. Fiel reflejo de dicha situación resultó, finalmente, el apartado I de la Exposición de Motivos del Real Decreto-ley 8/1997, al señalar lo siguiente:

«existe una patente demanda social, de cuya urgencia se hacen eco las Organizaciones empresariales y sindicales, en orden a la necesidad de acometer de manera decidida y urgente las oportunas reformas con el objetivo de luchar contra el paro, la precariedad laboral y la alta rotación de los contratos, y potenciar nuestra capacidad generadora de empleo, en especial de empleo estable».

11. Al mismo tiempo, el Real Decreto-ley 8/1997 se complementó con el Real Decreto-ley 9/1997, de 16 de mayo, sobre incentivos en materia de Seguridad Social y de carácter fiscal para el fomento de la contratación indefinida y la estabilidad en el empleo ${ }^{15}$.

En definitiva, puede estimarse que ambos reales decretos-leyes cumplían los requisitos constitucionales necesarios que deben justificar su utilización, en la medida en que la coyuntura económica exigía una rápida respuesta $^{16}$, y en la medida en que dicha respuesta no se hizo esperar, teniendo en cuenta el breve intervalo de tiempo transcurrido entre la constatación de los graves problemas que afectaban al mercado de trabajo y la adopción de las medidas para tratar de atajar tales problemas ${ }^{17}$.

Sin embargo, la reforma requirió para su consolidación la convalidación por las Cortes Generales, en tanto representantes de la soberanía popular. Así, una vez que los Grupos Parlamentarios mostraron su conformidad, en cierta medida condicionados por el éxito del diálogo social mantenido por el Gobierno y los interlocutores sociales más representativos de ámbito estatal, los reales decretos-leyes en cuestión se transformaron, respectivamente, en la Ley 63/1997, de 26 de diciembre, de medidas urgentes para la mejora del mercado de trabajo y el fomento de la contratación indefinida ${ }^{18}$, y en la Ley 64/1997, de 26 de diciembre, por la que se regulan incentivos en materia de

${ }^{15}$ BOE de 17 de mayo de 1997, núm. 118.

${ }^{16}$ Por todas, vid. STC 177/1990, de 15 de noviembre, Fundamento Jurídico 3. In Jurisprudencia Laboral en el Tribunal Constitucional. Vol. II (1989-1993) (GARCíA NiNET, J. I., Dir.) Valencia: Tirant lo Blach, 1995, p. 2086.

${ }^{17}$ Respecto al intervalo temporal como criterio de valoración de los presupuestos que deben concurrir en un real decreto-ley, vid., por todas, STC 23/1993, de 21 de enero, Fundamento Jurídico 4. In Jurisprudencia Laboral en el Tribunal Constitucional. Vol. II (19891993) (GARcía Ninet, J. I., Dir.). Valencia: Tirant lo Blach, 1995, p. 2665.

${ }^{18}$ BOE de 30 de diciembre de 1997, núm. 312. 
Seguridad Social y de carácter fiscal para el fomento de la contratación indefinida y la estabilidad en el empleo ${ }^{19}$.

12. Concretamente, de la Ley 63/1997 se deducía que el diálogo social debía perdurar más allá de la reforma en sí. Sin lugar a dudas, el ejemplo más claro de dicha perdurabilidad se encontraba en la Disposición Adicional primera de la ley, donde se regulaba el novedoso contrato para el fomento de la contratación indefinida. Pues bien, conforme a su apartado 6, una vez transcurridos cuatro años desde la entrada en vigor del Real Decreto-ley 8/1997, el Gobierno y las organizaciones sindicales y asociaciones empresariales más representativas de ámbito estatal debían proceder a evaluar conjuntamente los efectos de esta medida para el fomento de la contratación indefinida, a fin de proponer, en su caso, su eventual continuidad más allá del período de tiempo citado.

\subsection{La ruptura del diálogo social}

13. Por el contrario, y antes de que finalizase el mencionado período de cuatro años, el diálogo social quedo truncado. Tras un proceso negociador, que no llegó a buen fin, entre los agentes sociales más representativos a nivel estatal y el Gobierno, este último decidió unilateralmente «retocar» algunos aspectos de la reforma de 1997 que consideraba urgentes ${ }^{20}$.

Pese a tratarse de un mero «retoque», nuevamente se volvió a hablar de «reforma», y una vez más se recurrió a la figura del real decreto-ley, tal y como lo demuestra la entrada en vigor del Real Decreto-ley 5/2001, de 2 de marzo, de medidas urgentes de reforma del mercado de trabajo para el incremento del empleo y la mejora de su calidad ${ }^{21}$. En esta ocasión, el Gobierno se refirió a la urgencia de la adopción de las nuevas medidas «tanto para permitir su inmediata efectividad como para evitar distorsiones en el funcionamiento del mercado de trabajo» (Exposición de Motivos del Real Decreto-

\footnotetext{
${ }^{19}$ BOE de 30 de diciembre de 1997, núm. 312.

${ }^{20}$ Respecto al carácter unilateral de las medidas adoptadas por el Gobierno, caben plantearse tres cuestiones, con Alfonso Mellado: en primer lugar, las dudas acerca de la verdadera voluntad del Gobierno de proseguir avanzando en el diálogo social, tras las reiteradas manifestaciones del Gobierno de que si no se alcanzaba un acuerdo en un plazo corto procedería a regular él mismo los temas objeto de negociación; forma de proceder que, por otra parte, de ninguna de la maneras casa con el «afán de protagonismo» que gustan tener los agentes sociales. En segundo lugar, el coste social de la ruptura del diálogo social. En tercer lugar, las dudas acerca de si las nuevas medidas resultaban verdaderamente eficaces para reducir la elevada tasa de temporalidad existente (Alfonso Mellado, C. L. La primera reforma laboral del milenio. Comentarios al Real Decreto-ley 5/2001, de 2 de marzo. Valencia: Instituto Valenciano de Estudios Sociales, 2001, pp. 10-11).

${ }^{21}$ BOE de 3 de marzo de 2001, núm. 54.
} 
ley 5/2001). Del mismo modo, poco después, se procedió a la convalidación de dicho real decreto-ley por las Cortes Generales, dando lugar a la Ley $12 / 2001$, de 9 de julio ${ }^{22}$, de igual nombre que el real decreto-ley convalidado. Hecho que esta vez no contaba con el condicionamiento del apoyo de los agentes sociales, pero sí con la mayoría absoluta del Grupo Parlamentario coincidente con el partido gobernante.

14. Estas circunstancias hicieron que lo que en realidad se trataba de una línea continuista de la reforma de 1997, independientemente de que se compartiesen o no las nuevas medidas, se convirtiera en el inicio de un enfrentamiento que iba a prolongarse hasta el final de la legislatura.

Lo que años atrás se había aceptado con total naturalidad, a saber, echar mano del real decreto-ley, con el objetivo de ratificar bajo la forma de norma, y cuanto antes mejor, los acuerdos alcanzados mediante el diálogo

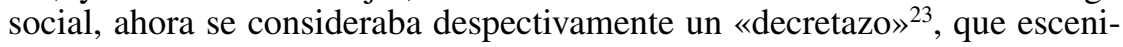
ficaba «la ruptura de las reglas implícitas sobre el modo en que habrían de producirse las variaciones en el sistema jurídico laboral» ${ }^{24}$.

La ruptura del diálogo social supuso el «atrincheramiento» momentáneo de los sindicatos más representativos a nivel estatal, que ya no se consideraban parte de un neocorporativismo de participación o cooperación, sino sujetos de contrapoder.

Los sindicatos, que hasta escasas fechas habían participado en el diálogo social con el Gobierno, denunciaban el carácter flexibilizador de las nuevas medidas y, especialmente, se posicionaban en contra de la ampliación del ámbito subjetivo del contrato de formación, del tratamiento dado al contrato a tiempo parcial y de la creación del contrato de inserción. Entendían que tales medidas contradecían la supuesta finalidad de favorecer un empleo estable y de más calidad, puesto que abrían nuevas vías de agua en el principio de estabilidad en el empleo y, con ello, daban nuevas alas a la contratación temporal. En resumen, la reforma parecía centrarse, en demasía, en la figura del contrato para el fomento de la contratación indefinida y en los estímulos a favor del empleo, y descuidaba aspectos tales como el refuerzo de la causalidad y del control de los contratos temporales, y la mejora de la regulación de las contratas y subcontratas ${ }^{25}$.

\footnotetext{
${ }^{22}$ BOE de 10 de julio de 2001, núm. 164.

${ }^{23}$ BARREIRo GonZÁleZ, G. «Sobre la extraordinaria y urgente necesidad de los decretosleyes». In Derecho Privado y Constitución, 2003, núm. 17, p. 47.

${ }^{24}$ Sempere Navarro, A. V. «Una Reforma vigésimosecular». In VV. AA. La reforma laboral de 2001 (Análisis del Real Decreto-ley 5/2001, de 2 de marzo). Pamplona: Aranzadi, 2001, p. 16.

${ }^{25}$ Escudero RodríGueZ, R. «Propósitos y despropósitos de la reforma laboral de 2001». In RL, 2001, vol I, pp. 1631-1685.
} 
15. Además, el ambiente se enrareció, más si cabe, cuando el Gobierno dictó de nuevo unilateralmente el Real Decreto-ley 5/2002, de 24 de mayo, de medidas urgentes para la reforma del sistema de protección por desempleo y mejora de la ocupabilidad ${ }^{26}$. Como si de la gota que colmase el vaso se tratara, los sindicatos con mayor representatividad a nivel estatal convocaron una huelga general de protesta en el Estado para el 20 de junio de 2002, y solicitaron la retirada del nuevamente considerado «decretazo».

16. En este clima revuelto, hicieron acto de presencia, igualmente, algunos sindicatos periféricos, que gozaban en la correspondiente comunidad autónoma del grado de más representativos. Quizás el caso más paradigmático fue el de ELA, en la Comunidad Autónoma del País Vasco.

ELA, que ya venía denunciando desde años atrás una «oleada neoliberal», de la que consideraba partícipes a los sindicatos de mayor representatividad a nivel estatal, no se sumó a la protesta de tales sindicatos. El sindicato de corte nacionalista consideró interesada la postura de los sindicatos centralistas, al entender que cuando éstos «se vieron desalojados de los ámbitos de influencia y reducidos a la irrelevancia, se opusieron a... [la reforma]». Realmente, ELA veía necesaria la huelga, pero entendió que los sindicatos centralistas se encontraban animados por una razón muy distinta a la suya: recuperar el dialogo social roto unilateralmente por el Gobier$\mathrm{no}^{27}$.

Por ello, ELA, al igual que LAB, decidió convocar también una huelga general, pero ampliando los motivos, y adelantando en un día la convocatoria en las comunidades autónomas en las que opera, es decir, País Vasco y Navarra. De este modo, la convocatoria de huelga realizada por ELA fue más allá de la protesta por la reforma y, en realidad, fue utilizada como arma arrojadiza en contra de los efectos negativos que, a su entender, se habían derivado del diálogo social mantenido en los últimos años entre el Gobierno y los sindicatos centralistas de máxima representatividad ${ }^{28}$.

\subsection{La recuperación del diálogo social y la reforma de 2006}

17. Apenas trascurridos dos meses desde el inicio de la actual legislatura, a mediados de 2004 se retomó el diálogo social entre el Estado y los agentes

${ }^{26}$ BOE de 25 de mayo de 2002, núm. 125. Respecto a las novedades que introdujo este real decreto-ley véase SoSA MANCHA, M. T. «La reforma de la protección por desempleo. Breve análisis del Real Decreto-ley 5/2002, de 24 de mayo». In AS, 2002, vol. v, Estudios e Índices, pp. 773-804.

${ }^{27}$ LeTAMENDia BelzunCE, F. ELA 1976-2003. Sindicalismo de contrapoder. Bilbao: Fundación Manu Robles-Arangiz Institutua, 2004, p. 251.

${ }^{28} \mathrm{Al}$ respecto véase Letamendia Belzunce, F. ob. cit., p. 252. 
sociales con mayor representatividad a nivel estatal. No obstante, esta nueva etapa presenta, a priori, especiales características.

El punto de partida de esta nueva etapa lo constituyó la Declaración para el Diálogo Social, de 8 de julio de 2004: Competitividad, Empleo Estable y Cohesión Social ${ }^{29}$. Las peculiaridades que presenta esta Declaración se han reflejado correctamente, al ser considerada como «acuerdo general del diálogo social» ${ }^{30}$.

Efectivamente, el objetivo de la Declaración no ha sido que las partes aborden directamente el tipo de medidas a adoptar para solucionar las cuestiones objeto de diálogo. Esa había sido, hasta el momento, la forma de proceder en tales procesos. Además, en esta ocasión, el Gobierno participa directamente, y desde el inicio, en el diálogo, de igual a igual con los otros interlocutores, a saber, CEOE y CEPYME, por la parte empresarial, y UGT y CC. OO., por la parte sindical.

En este caso, como gran novedad metodológica, en lugar de comenzar la tarea de negociar las materias concretas, las partes han optado por fijar las bases o filosofía general de un proceso de concertación amplio, para que se pueda ir desarrollando poco a poco a lo largo de toda la legislatura ${ }^{31}$. En conclusión, esta declaración se sitúa en la categoría de los denominados «instrumentos marco» ${ }^{32}$. Con ello, se inicia un proceso abierto de negociación tripartita sobre materias diversas para ser tratadas en mesas diferentes, en las que cabrá la posibilidad de llegar a acuerdos sociopolíticos, convertibles, en su caso, en disposiciones jurídicas.

Así, la reforma del mercado de trabajo ha sido una de las materias objeto de debate en una de esas mesas, de forma y manera que el acuerdo alcanzado se ha convertido, primero, en el Real Decreto-ley 5/2006 de 9 de junio, y, después, en la Ley 43/2006, de 29 de diciembre. En realidad, la Ley 43/2006 introduce pocos cambios respecto al Real Decreto-ley 5/2006, limitándose a consolidarlo ${ }^{33}$.

${ }^{29}$ Puede consultarse en VV. AA. La reforma laboral de 2006. Análisis del Real Decreto-ley 5/2006, de 9 de junio (SEmpere NaVArro, A.V., Dir.). Pamplona: Aranzadi, monografías Punto de Actualidad, 2006, pp. 261-266.

${ }^{30}$ CRUz Villalón, J. ob. cit., p. 16.

${ }^{31}$ Ibidem.

32 Pedrajas Moreno, A., Sala Franco, T. y Valdés Dal-Re, F. La reforma laboral 2006. Valencia: Tirant lo Blanch, 2006, p. 27.

${ }^{33}$ La evolución del diálogo social en lo que respecta a la reforma del mercado de trabajo se recoge en las exposiciones de motivos del Real Decreto-ley 5/2006 y de la Ley 43/2006.

De este modo, una vez adoptada la Declaración para el Diálogo Social sobre la Competitividad, el Empleo estable y la Cohesión Social, de 8 de julio de 2004, el diálogo sobre la reforma del mercado de trabajo se inició encomendando a una comisión de expertos la realización de un informe para evaluar el funcionamiento de las políticas de empleo desde las reformas laborales acometidas en el período 1992-1994 hasta la actualidad. Esta comisión 
Con ello, se observa claramente que la denominada reforma laboral de 2006 se encuadra en el fenómeno más amplio de la nueva etapa de diálogo social, a desarrollarse de manera indeterminada, por lo menos, durante toda la legislatura. Por consiguiente, muchas de las materias tratadas en otras mesas también tienen una indiscutible repercusión en el mercado de trabajo, por lo que resulta fundamental tener en cuenta el resto de los acuerdos alcanzados, así como los que vayan surgiendo en el futuro ${ }^{34}$. Sólo así podrán valorarse en su integridad los resultados de la actual etapa de diálogo social.

18. De todos modos, de entrada, no deja de ser chocante que otra vez se haya recuperado el diálogo social en un período en el que el Gobierno cuenta con minoría parlamentaria, tal y como sucedió en la reforma de 1997, o en la época de la primera concertación social ${ }^{35}$. En efecto, independientemente del color político, los Gobiernos han actuado del mismo modo, acudiendo a la concertación o al diálogo social en períodos con escasos apoyos en el parlamento, y «arrinconándola» en períodos de mayoría absoluta en el parlamento. Esta tendencia no hace más que suscitar desconfianza.

Asimismo, para la actual reforma del mercado de trabajo se ha vuelto a recurrir inicialmente a un real decreto-ley, sin que, en esta ocasión, nadie haya mencionado el término «decretazo». Tampoco los motivos argumentados por el Gobierno para acudir a esta técnica legislativa resultan del todo convincentes, si se tiene en cuenta, por una parte, que «entre el momento de preparación y el de publicación no media un lapso capaz de llamar a la alarma ${ }^{36}, y$, por otra parte, en algunos de los temas abordados por la reforma «media la remisión a un desarrollo ulterior, síntoma evidente de la falta de

de expertos entregó el 31 de enero de 2005 su informe «Más y mejor empleo en un nuevo escenario socioeconómico: por una flexibilidad y seguridad laborales efectivas». A la luz de dicho informe, los firmantes de la Declaración de 8 de julio de 2004, analizaron la situación, estudiaron las soluciones y tras un proceso negociador plantearon ciertas medidas en el «Documento para el Diálogo Social sobre el Mercado de Trabajo», de 15 de marzo de 2005». Dicho documento dio lugar al «Documento para la mesa de Diálogo Social sobre Mercado de Trabajo», de 18 de octubre de 2005, y, finalmente, el 9 de mayo de 2006, se adoptó el «Acuerdo para la mejora del crecimiento y del empleo», posteriormente transformado en el Real Decreto-ley 5/2006, y en la Ley 43/2006. Todos estos documentos pueden consultarse en VV. AA. La Reforma Laboral de 2006. Análisis del Real Decreto-ley 5/2006, de 9 de junio (Sempere Navarro, A.V., Dir.). Cizur Menor: Aranzadi, 2006, pp. 261-313.

${ }^{34}$ Sobre las diferentes materias tratadas en las correspondientes mesas de diálogo, véase Cruz Villalón, J. ob. cit., pp. 18-19. Igualmente, se hace referencia a tales materias en Pedrajas Moreno, A., Sala Franco, T. y Valdés Dal-Re, F. ob. cit., pp. 32-33.

${ }^{35}$ A tal conclusión se llega también en Pedrajas Moreno, A., Sala Franco, T. y ValDÉS DAL-RE, F. ob. cit., p. 17.

${ }^{36}$ FERnÁNDEZ DomíngueZ, J.J. Presentación a la obra Aspectos puntuales de la Reforma Laboral de 2006. Análisis del Real Decreto-ley 5/2006 (FERnÁndeZ DomíngueZ, J. J., Dir. y Coord.). Murcia: Ediciones Laborum, 2006, p. 20. 
verdadera premura ${ }^{37}$. Ciertamente, la utilización abusiva que en los últimos tiempos se está haciendo del real decreto-ley resulta preocupante, pues desborda en muchos casos su verdadera operatividad ${ }^{38}$.

Por otro lado, puede resultar curioso que a pesar de que el diálogo social se haya llevado a cabo sin contar con las comunidades autónomas ni con los agentes sociales de mayor representatividad en ellas, la correcta aplicabilidad de la Ley 43/2006 requiera ineludiblemente de su coordinación, como sucede en el caso de los Servicios Públicos de Empleo. Por ello, no es de extrañar que algunos sindicatos de mayor representatividad en las comunidades autónomas pretendan bloquear algunas de las medidas derivadas de la actual reforma, ante todo por su falta de participación en el proceso. Se volverá a repetir, con toda seguridad, la misma escena de épocas anteriores, en la que tales sindicatos criticarán la participación y cooperación de las centrales estatales con el Gobierno, al tiempo que denunciarán la flexibilización de las relaciones laborales y el abaratamiento del despido como armas a su favor.

Sin lugar a dudas, la compleja estructura del Estado requiere la adopción de compromisos en todas las direcciones y por parte de todos los implicados, porque o sinceramente se cree en ella como mecanismo de engranaje de la mayor y más importante maquinaria de producción y bienestar social, que es la convivencia racional, o nada tiene sentido.

Resumiendo, esta relación de amor-odio existente entre los agentes sociales y el Gobierno, así como entre los propios agentes sociales de distinto ámbito, pone en duda la madurez no ya sólo de los sindicatos, sino que también del propio sistema de representatividad, para defender con sinceridad y garantía los intereses de los trabajadores de base, a los que únicamente debe su razón de ser el Derecho sindical ${ }^{39}$.

19. En este contexto, la situación es la que es, y las medidas adoptadas son las que son, por lo que en los siguientes apartados se comentarán, aunque sea sucintamente, las medidas más significativas de la reforma del mercado de trabajo contenidas en un primer momento en el Real Decreto-ley 5/2006, y, en la actualidad, en la Ley 43/2006.

\footnotetext{
${ }^{37}$ FeRnández DomíngueZ, J. J. ob. cit., pp. 21-22.

${ }^{38}$ En torno a la aplicabilidad de los decretos-leyes resulta de máximo interés SANTOLAYA MACHETTI, P. El régimen constitucional de los decretos-leyes. Madrid: Tecnos, 1988, 270 pp. También puede consultarse CARMONA CONTRERAS, A. M. La configuración constitucional del Decreto-ley. Madrid: Centro de Estudios Políticos y Constitucionales, 1997, p. 380. De forma más resumida, pero no menos interesante, se refiere a la cuestión SALAS, J. «Los Decretosleyes en la teoría y en la práctica constitucional». In Estudios sobre la Constitución Española. Homenaje al profesor Eduardo García de Enterría. Tomo I, pp. 267-326. Por último, también debe traerse a colación el artículo doctrinal ya citado de BARREIRO GonZÁLEZ, G.

${ }^{39}$ Para una visión crítica y alternativa sobre esta cuestión, vid. Álvarez Cuesta, H. Puntos críticos y alternativas a las elecciones sindicales y a la mayor representatividad. Granada: Editorial Comares, 2006, p. 221.
} 


\section{Medidas adoptadas para fomentar la contratación indefinida}

20. La actual reforma del mercado de trabajo presenta un «prisma continuista» en relación con los objetivos perseguidos en la reforma de $1997^{40}$. De ahí que no se hayan introducido grandes cambios y se siga apostando supuestamente por fomentar la contratación indefinida. En concreto, las medidas adoptadas pretenden impulsar la contratación indefinida inicial o directa, favorecer la conversión del empleo temporal en fijo y apoyar con fondos públicos la contratación estable.

No resulta extraño que se siga en esta línea, teniendo en cuenta el desolador panorama que presenta el mercado de trabajo español. Además de poseer las mayores tasas de paro y precariedad de la Unión Europea, cuenta con los menores porcentajes de población activa femenina y de natalidad ${ }^{41}$. Esta situación, que perdura durante casi ya tres décadas, tiene mucho que ver con «el círculo vicioso» que comienza con el reconocimiento de la temporalidad contractual en la lucha contra el paro, pasa por el «acomodamiento» de los empresarios en la «cultura de la temporalidad», y termina en la precariedad que sufren los trabajadores ${ }^{42}$.

La cuestión se centra ahora en la viabilidad de las medidas adoptadas en la actual reforma, puesto que las existentes hasta la fecha no han resultado efectivas. La desventaja de las actuales medidas es que prosiguen en la misma línea que las anteriores, y que, por ende, actúan no sólo contrarreloj, sino que entran en acción cuando el reloj lleva ya bastante tiempo en marcha.

${ }^{40}$ De La Puebla Pinilla, A. y Pérez Yánez, R. «El Acuerdo para la mejora del crecimiento y del empleo de 9 de mayo de 2006, ¿una mínima reforma o una reforma de mínimos?» In RL, 2006, núm. 12, pp. 36-37.

41 Martínez Barroso, R. "Fomento de la contratación indefinida y conversión del empleo temporal en fijo». In Aspectos puntuales de la Reforma Laboral de 2006. Análisis del Real Decreto-ley 5/2006 (FERnÁndez DomíngueZ, J. J., Dir. y Coord.). Murcia: Ediciones Laborum, 2006, pp. 41-42.

${ }^{42}$ Un interesante punto de partida sobre esta situación en CASAS BAAMONDE, M. E. y VALDÉS DAL-RE, F. «Diversidad y precariedad de la contratación laboral en España». In RL, 1989, vol. I, pp. 240-258.

Mención especial merecen en este punto los comentarios realizados por DE LA VILLA GIL, quien considera, por una parte, que «el empresario español no está dispuesto a celebrar contratos de trabajo por tiempo indefinido porque el coste de su ruptura es, asimismo, el más alto de la Unión Europea», y, por otra parte, que «un altísimo porcentaje del empresariado español se ha acostumbrado a contratar fuera de la ley... Y ello porque la probabilidad de que dicha irregularidad se detecte es bajísima habida cuenta del número total de las contrataciones precarias». Con todo ello, llega a concluir que «la mejor defensa de la precariedad es la precariedad misma, en cuanto que a medida que la precariedad de la contratación aumenta, la aplicación de la ley es menos viable y eficaz» (DE LA VILLA GIL, L. E. «¿Acabar con el trabajo precario, I? Notas de urgencia a la reforma laboral de 2006». In Revista General de Derecho del Trabajo y de la Seguridad Social, 2006, núm. 11, pp. 2-4). 
21. En este sentido, entre las medidas adoptadas, cabe señalar que se consolida el contrato para el fomento de la contratación indefinida, ya que se asume íntegramente el régimen jurídico vigente de esta modalidad contractual. Por tanto, seguirá rigiendo lo establecido en la Disposición Adicional primera de la Ley 12/2001 de 9 de julio. Como novedad, se amplía hasta el 31 de diciembre de 2007 el plazo dentro del cual pueden celebrarse contratos temporales que, posteriormente, y en la misma empresa, podrán convertirse en contratos para el fomento de la contratación indefinida. Debe recordarse que, con anterioridad al Real Decreto-ley 5/2006, la fecha que había que tener en cuenta a estos efectos era el 31 de diciembre de 2003.

Con la prolongación de esta fecha, en realidad, se favorece la contratación temporal y se retrasa la contratación indefinida inicial de un mismo sujeto. Además, la posterior conversión en contrato para el fomento de la contratación indefinida lleva aparejada la ventaja de un despido más barato.

22. Igualmente, para impulsar la contratación indefinida se ha regulado un nuevo Programa de Fomento del Empleo, que presenta importantes novedades respecto al inicialmente previsto en la Disposición Adicional quincuagésima de la Ley 30/2005, de 29 de diciembre, de Presupuestos Generales del Estado para el año $2006^{43}$.

Sobre todo, con el nuevo programa se ha modificado el sistema de incentivos a la contratación indefinida, conforme a los siguientes criterios ${ }^{44}$ : a) seleccionar mejor los colectivos beneficiarios, extendiendo su aplicación a los jóvenes de 16 a 30 años, hasta hoy excluidos de éstos; b) simplificar los incentivos; c) ampliar la duración de las bonificaciones con el objetivo de favorecer el mantenimiento del empleo; d) sustituir los porcentajes de bonificación actuales por cuantías fijas de subvención.

23. Además de estos principios, la gran novedad reside en que, como norma general, los incentivos se conceden exclusivamente para los contratos indefinidos, tanto a tiempo completo como a tiempo parcial e incluida la modalidad de fijo discontinuo, con lo que se pretende fomentar esta modalidad contractual ab initio.

Ahora bien, cabe cuestionar la eficacia de esta medida por los efectos negativos que conlleva. Así, por un parte, esta medida abre las puertas a la «posibilidad de otorgar incentivos a contrataciones que se hubieran realizado aun sin la existencia de las mismas ("peso muerto")» ${ }^{45}, y$, por otra parte, «los recursos dedicados a estos fines han de ser financiados con impuestos

${ }^{43}$ BOE de 30 de diciembre de 2005, núm. 312.

${ }^{44}$ Estos criterios se recogen en el Acuerdo para la Mejora del Crecimiento y del Empleo, de 9 de mayo de 2006.

${ }^{45}$ Martínez Barroso, R. ob. cit., p. 75. 
que recaen sobre todas las empresas y sus empleados, tanto si perciben estímulos como si no, generando el llamado "efecto desplazamiento"» ${ }^{46}$. Igualmente, en ambos casos se aprecia una total dejadez, al no profundizar en el análisis de cada zona geográfica o de cada sector de la producción, donde resulta fundamental el quehacer de las comunidades autónomas y de los agentes sociales con mayor representatividad en ellas ${ }^{47}$.

Sin que se detallen aquí los incentivos regulados para fomentar la contratación indefinida y su duración, puesto que se da cuenta de ellos en el Anexo de esta exposición, llama la atención que se siga manteniendo el concepto «bonificaciones» para designar lo que realmente pasan a ser «subvenciones». Ciertamente, otra de las grandes novedades de la reforma ha consistido en «volcar el esfuerzo económico sobre las subvenciones, es decir, sobre las entregas de cantidades de dinero a tanto alzado por la celebración de determinados contratos, abandonando la anterior política de bonificar las cuotas de Seguridad Social cuando dichos contratos fueran concertados ${ }^{48}$. No obstante, la Ley 43/2006 introduce una excepción a dicha regla general, al señalar que «no se sustituyen los porcentajes de bonificación por cuantías fijas de... [subvención], en el caso de la contratación de personas con discapacidad por los centros especiales de empleo» (apartado IV de la Exposición de Motivos).

En lo que respecta a la materialización práctica de estas subvenciones, en primer lugar, hay que tener en cuenta que se financiarán con cargo a la correspondiente partida presupuestaria del Servicio Público de Empleo Estatal (apartado 1 de la Disposición Adicional tercera de la Ley 43/2006). Posteriormente, serán los empresarios quienes descontarán las cuantías a disfrutar de los correspondientes documentos de cotización (apartado 2 de la Disposición Adicional tercera de la Ley 43/2006). Por último, con la finalidad de garantizar la correcta administración de estos recursos y evitar el fraude, se establecen ciertas obligaciones de control y revisión a la Inspección de Trabajo y Seguridad Social, a la Tesorería General de la Seguridad Social y al Servicio Público de Empleo (apartados 3 y 4 de la Disposición Adicional tercera de la Ley 43/2006).

Los beneficiarios de estas subvenciones son las empresas, incluidos los trabajadores autónomos, y sociedades laborales o cooperativas a las que se incorporen trabajadores como socios trabajadores o de trabajo, siempre que estas últimas hayan optado por un régimen de Seguridad Social propio de trabajadores por cuenta ajena (artículo 1.3, párrafo primero, de la Ley 43/2006). Además, la Ley 43/2006 va más lejos que el Real Decreto-ley $5 / 2006$, pues considera igualmente beneficiarios a las empresas, incluidos

${ }^{46}$ Martínez Barroso, R. ob. cit., p. 76.

${ }^{47}$ En este sentido véase MARTínez Barroso, R. ob. cit., p. 75.

${ }^{48}$ De La Villa Gil, L. E. ob. cit., p. 5. 
los trabajadores autónomos, y sociedades laborales y cooperativas mencionadas, en el caso de transformación de contratos temporales en contratos o vínculos societarios indefinidos (artículo 1.3, párrafo segundo).

Ello no obstante, los beneficiarios deberán cumplir los requisitos de hallarse al corriente en el cumplimiento de sus obligaciones tributarias y de Seguridad Social, y de no haber sido excluidos del acceso a los beneficios derivados de la aplicación de los programas de empleo por la comisión de infracciones muy graves no prescritas (artículo 5 de la Ley 43/2006). En todo caso, quedan excluidos de los beneficios la Administración General del Estado y los Organismos regulados en el Título III y en la Disposición Adicional décima de la Ley 6/1997, de 14 de abril, de Organización y Funcionamiento de la Administración General del Estado ${ }^{49}$, así como las Administraciones Autonómicas y las Entidades Locales y sus Organismos públicos (artículo 1.4 de la Ley 43/2006).

En lo que respecta al ámbito de aplicación u objeto de las subvenciones, el nuevo Programa de Fomento del Empleo parte del sentir generalizado según el cual «uno de los tradicionales problemas del modelo español de incentivos a la contratación indefinida es la imprecisa y poco meditada identificación de los colectivos de trabajadores cuya contratación debe estimularse mediante beneficios económicos a las empresas ${ }^{50}$. Por ese motivo, se pretende la reagrupación y simplificación de los colectivos de trabajadores cuya contratación da derecho a percibir incentivos a la empresa.

Si bien estos colectivos se detallan en el Anexo, deben destacarse las siguientes novedades:

a) Se incluyen las mujeres, sin ulteriores requisitos; b) en lugar de referirse a los minusválidos, se alude a las personas con discapacidad, distinguiéndose, a efectos de las correspondientes subvenciones, entre las personas con discapacidad genérica, los trabajadores con discapacidad incluidos en alguno de los grupos específicos determinados en la propia Ley 43/2006 y los discapacitados contratados por un centro especial de empleo ${ }^{51}$; c) reconociendo las relaciones entre las políticas de empleo y la política social, se

${ }^{49}$ BOE de 15 de abril de 1997, núm. 90.

${ }^{50}$ LuJÁN AlCARAZ, J. «Las medidas de impulso a la contratación indefinida». In VV. AA. La reforma laboral de 2006. Análisis del Real Decreto-ley 5/2006, de 9 de junio (SEMPERE Navarro, A.V., Dir.). Pamplona: Aranzadi, monografías Punto de Actualidad, 2006, p. 55.

${ }^{51}$ Debe recordarse que tradicionalmente, el fomento del empleo de las personas con discapacidad ha discurrido por sus propios cauces, fuera de los programas generales de fomento del empleo (Luján AlCARAZ, J. ob. cit., pp. 59-61).

Ahora, tras el Real Decreto-ley 5/2006, la Ley 43/2006 define, a sus efectos, como trabajadores discapacitados a las personas que tengan reconocido «un grado de minusvalía igual o superior al 33 por ciento o la específicamente establecida en cada caso», y a «los pensionistas de la Seguridad Social que tengan reconocida una pensión de incapacidad permanente en el grado de total, absoluta o gran invalidez, así como [a] los pensionistas de clases 
incluye a las víctimas de violencia de género y de violencia doméstica, sin necesidad de hallarse desempleadas ${ }^{52}$; d) aunque se continúa con la tendencia a incentivar la contratación de los mayores de 45 años, desaparece la distinción entre los mayores de 45 hasta los 55 años y los mayores de 55 hasta los 65 años, en la línea con las modernas tendencias a alargar la vida laboral y favorecer la jubilación gradual y flexible.

24. Junto a los incentivos a la contratación indefinida inicial, se regulan en el nuevo Programa de Fomento del Empleo las subvenciones y bonificaciones para el mantenimiento del empleo de determinados trabajadores (artículos 1 y 4 de la Ley 43/2006), y con carácter excepcional, las subvenciones -mal denominadas bonificaciones- para los contratos temporales que se celebren con trabajadores con discapacidad o con personas que se encuentren en situación de exclusión social ${ }^{53}$, siempre que, en ambos casos, estén desempleados e inscritos en la Oficina de Empleo, así como con personas que tengan acreditada la condición de víctima de violencia de genero en los términos de la Ley Orgánica 1/2004, o de víctima de violencia de género (artículos 1.2 y 2 de la Ley 43/2006). Todos estos colectivos, así como las

pasivas que tengan reconocida una pensión de jubilación o de retiro por incapacidad permanente para el servicio o inutilidad» (artículo 2.2.5).

Igualmente, debe destacarse que, en comparación con el Real Decreto-ley 5/2006, la Ley 43/2006 incrementa los incentivos por la contratación de trabajadores discapacitados, al tiempo que sustituye la indeterminada alusión de «trabajadores con discapacidad con especiales dificultades para el acceso al mercado ordinario de trabajo, procedentes de enclaves laborales», a través de la cual se aumentaban los incentivos por la contratación de trabajadores aquejados de una discapacidad severa, por la concreción de los determinados grupos que dan lugar al aumento de los incentivos.

${ }^{52}$ Resultan interesantes las apreciaciones que al respecto realiza LUJÁN ALCARAZ, al recordar que al incluir a las víctimas de violencia doméstica, junto a las víctimas de violencia de género...

«se amplía el elenco de personas cuya contratación laboral puede ser objeto de bonificación pues, como es sabido, la noción de violencia de género que resulta de la Ley Orgánica 1/2004 [de 28 de diciembre, de Medidas de Protección Integral contra la Violencia de Genero (BOE de 29 de diciembre de 2004, núm. 313)] es mucho más técnica y restrictiva que la de violencia doméstica. La primera, en efecto, se refiere a "todo acto de violencia física y psicológica, incluidas las agresiones a la libertad sexual, las amenazas, las coacciones o la privación arbitraria de libertad" que "como manifestación de la discriminación, la situación de desigualdad y las relaciones de poder de los hombres sobre las mujeres, se ejerce sobre éstas por parte de quienes sean o hayan sido sus cónyuges o de quienes estén o hayan estado ligados a ellas por relaciones similares de afectividad, aun sin convivencia (artículo 1, apartados 3 y 1 de la Ley Orgánica 1/2004). En cambio, la expresión violencia doméstica "hace referencia a la que se produce en el seno del hogar, pudiendo acontecer contra mujeres por parte del varón (en este caso violencia de género), contra las personas dependientes o, incluso, contra los padres o hermanos"» (LUJÁn AlCARAZ, J. ob. cit., pp. 61-62).

${ }^{53}$ Se entienden por tales los incluidos en los colectivos relacionados por la Disposición Adicional segunda de la Ley 43/2006. 
cuantías a las que da lugar su contratación y la duración de su percepción se recogen en el Anexo.

25. Por último, y también con carácter excepcional, además de limitado en el tiempo, el nuevo Programa de Fomento del Empleo regula un «Plan extraordinario para la conversión de empleo temporal en fijo», conforme al cual los contratos de duración determinada o temporal, incluidos los formativos, de relevo y de sustitución por jubilación, celebrados con anterioridad al 1 de junio de 2006 que se transformen en indefinidos antes del 1 de enero de 2007, darán derecho a las subvenciones indicadas en el Anexo (artículo 3 de la Ley 43/2006). En último término, con este plan parece ser que se pretende «drenar la bolsa de contratos de trabajo temporales existentes y reducir drásticamente la temporalidad» ${ }^{54}$.

\section{Modificaciones introducidas para mejorar la utilización de la contra- tación temporal}

26. La Ley 43/2006, al igual que el Real Decreto-ley 5/2006, establece una batería de medidas para intentar limitar la contratación temporal y ajustarla a un uso razonable. Concretamente, es en este ámbito donde, a primera vista, se recogen las medidas más espectaculares, tales como la tan ansiada limitación a la concatenación de contratos temporales, el reforzamiento de los derechos de los trabajadores en contratas y subcontratas y la definición de cesión ilegal. Sin embargo, junto a tales medidas, se han adoptado otras que quizás llamen menos la atención, pero que no por ello dejan de ser menos interesantes. Es el caso de la fulminante desaparición del contrato del inserción, o de la supuesta reorientación del contrato para la formación. A todos ellos nos referiremos a continuación.

\subsection{La fulminante desaparición del contrato de inserción}

27. El contrato de inserción ${ }^{55}$, introducido como modalidad contractual por la reforma laboral de 2001, desaparece con la nueva reforma, pues la

\footnotetext{
${ }^{54}$ Pedrajas Moreno, A., Sala Franco, T. y Valdés Dal-Re, F. La reforma laboral 2006. Valencia: Tirant lo Blanch, 2006, p. 65.

${ }^{55}$ Sobre esta modalidad contractual pueden consultarse las siguientes monografías: SIRVENT HERNÁNDEZ, N. El contrato de inserción laboral y los programas públicos de mejora de la ocupabilidad. Valencia: Tirant lo Blach, 2004, 212 pp.; Soler ArReBolA, J. A. El contrato de inserción laboral en el contexto de las políticas activas de empleo. Murcia: Ediciones Laborum, 2004, 194 pp. También puede consultarse ToROLlo GonZÁLEZ, F. J.«El contrato de inserción». In AS, 2001, vol. v, Estudios e Índices, pp. 643-683.
} 
Disposición Derogatoria única tanto del Real Decreto-ley 5/2006 como de la Ley 43/2006 deroga el precepto destinado a su regulación, es decir, el artículo 15.1.d del texto refundido de la Ley del Estatuto de los Trabajadores, aprobado por Real Decreto Legislativo 1/1995, de 24 de marzo (TRLET) ${ }^{56}$. Al mismo tiempo, desaparecen las referencias a esta modalidad contractual contenidas en los artículos 8.2, 15.6 y 49.1.c del TRLET.

28. No obstante, llama la atención la distinta valoración que se ha realizado sobre la desaparición de esta modalidad contractual. Para empezar, resulta chocante que mientras en el apartado IV de la Exposición de Motivos tanto del Real Decreto-ley 5/2006 como de la Ley 43/2006 se señala respecto al contrato de inserción «que no ha cumplido las expectativas para las que se había creado», en el informe de la comisión de expertos para el diálogo social, Más y mejor empleo en un nuevo escenario socioeconómico: por una flexibilidad y seguridad laborales efectivas, se considerase necesario potenciar su utilización, elaborando y aprobando el oportuno desarrollo reglamentario, anunciado desde 2001 y no materializado, con el fin un tanto rebuscado de que el contrato para la formación recuperara su identidad propia, contaminada con ciertos elementos propios de una lógica de inserción ${ }^{57}$.

Por su parte, mientras que algunos autores han manifestado no entender con claridad la razón de tal derogación, «puesto que se estaba ante una modalidad contractual que había gozado de un nivel suficiente de utilización ${ }^{58}$, otros han preferido hablar de «crónica de una derogación anunciada» ${ }^{59}$, o de «decisión técnicamente acertada», al considerar, en este último caso, que las medidas de insertación han de instrumentarse a través de negocios jurídicos distintos al contrato de trabajo ${ }^{60}$.

29. En resumen, aunque se echa en falta la justificación del Gobierno para aclarar la decisión de derogar el contrato de inserción, debe reconocerse que son muchos los motivos que, en la práctica, justifican dicha decisión, más allá de que suponga la eliminación de un contrato temporal, en sintonía

${ }^{56}$ BOE de 28 de marzo de 1995, núm. 75.

57 TASCÓN LÓPEZ, R. «Reformas en materia de contratación temporal». In Aspectos puntuales de la Reforma Laboral de 2006. Análisis del Real Decreto-ley 5/2006 (FERNÁNDEZ DomíngueZ, J.J., Dir. y Coord.). Murcia: Ediciones Laborum, 2006, pp. 109-110.

58 Pedrajas Moreno, A., Sala Franco, T. y Valdés Dal-Re, F. La reforma laboral 2006. Valencia: Tirant lo Blanch, 2006, p. 87.

59 PÉREZ YÁneZ, R. «Adaptaciones en los contratos formativos y de inserción». In VV. AA. La Reforma Laboral de 2006. Real Decreto Ley 5/2006, de 9 de junio (CRUZ VILLALÓN, J., Coord.). Valladolid: Lex Nova, 2006, pp. 118-119. En el mismo sentido, De LA PuEBla Pinilla, A. y Pérez Yánez, R. ob. cit., pp. 50-51.

${ }^{60}$ Sempere NAVArRo, A.V. «Limitaciones a la contratación temporal». In VV. AA. La reforma laboral de 2006. Análisis del Real Decreto-ley 5/2006, de 9 de junio (SEMPERE NAVARRO, A.V., Dir.). Pamplona: Aranzadi, monografías Punto de Actualidad, 2006, pp. 82-83. 
con una reforma que pretende fomentar el empleo estable. En concreto, la doctrina ha llamado la atención sobre los siguientes puntos débiles del contrato de inserción ${ }^{61}$ : la discrecionalidad en la elección de los posibles beneficiarios; la excesiva amplitud de su objeto; el dilatado elenco de destinatarios; las consecuencias negativas derivadas de su escasez de costes; la ausencia de indemnización a la finalización del contrato; la presunción iuris tantum sobre la indefinición de la relación laboral y su destrucción de facto; y las incertidumbres sobre su duración.

Ello no obstante, como medida transitoria, los contratos de inserción concertados con anterioridad al 15 de junio de 2006 (fecha de entrada en vigor del Real Decreto-ley 5/2006) se regirán por la normativa legal o convencional vigente en la fecha en que se celebraron (Disposición Transitoria primera de la Ley 43/2006).

Por todo ello, no se entiende muy bien el sentido de la Disposición Final quinta de la Ley 43/2006, relativa a la «contratación de trabajadores en situación de exclusión social». En realidad, la regulación de esta nueva figura contractual podría anticipar la aparición de una figura semejante al contrato de inserción. Así, conforme a la Disposición Final quinta de la Ley 43/2006, el Gobierno, en el plazo de seis meses desde la aprobación de dicha ley, y previa consulta con las organizaciones sindicales y asociaciones empresariales más representativas, aprobará una norma con rango de ley para regular el régimen de las empresas de inserción, con el fin de facilitar el empleo de los trabajadores que se encuentren en situación de exclusión, conforme a la Disposición Adicional segunda de la Ley 43/2006.

\subsection{La supuesta reorientación del contrato para la formación}

30. Mediante la actual reforma laboral se pretende reorientar el contrato para la formación hacia su auténtica esencia, a saber, la adquisición de la formación teórica y práctica necesaria para el desempeño adecuado de un oficio o puesto de trabajo que requiera un determinado nivel de cualificación. Con otras palabras, se pretende reforzar el carácter formativo de esta modalidad contractual frente al carácter de inserción o de fomento del empleo que había prevalecido en la reforma de $2001^{62}$.

${ }^{61}$ TASCón LóPEZ, R. ob. cit., pp. 112-119.

${ }^{62}$ Respecto a las consecuencias de la reforma laboral de 2001 en el contrato para la formación, véase GoÑI SEIN, J. L. «Los contratos formativos en la Ley 12/2001: alteraciones en el ámbito subjetivo». In RL, 2002, vol. I, pp. 575-595. En concreto, dicho autor hace hincapié, con motivo de la reforma de 2001, en que «aun cuando la prioridad política fundamental [del momento] sea la de dar trabajo a los colectivos desfavorecidos, la dimensión formativa, que es lo que caracteriza a este contrato, debe estar siempre presente» (p. 582). 
En esa línea, las principales medidas de la reforma han consistido, por una parte, en la regulación de ciertos límites de edad para que una serie de trabajadores puedan realizar esta modalidad contractual, $y$, por otra parte, en la exclusión de algunos colectivos del ámbito de aplicación de este contrato, que tienen que ver más con políticas de empleo que con políticas formati$\operatorname{vas}^{63}$.

31. Así, en lo que respecta a los límites de edad, en principio, se mantiene el criterio general, conforme al cual podrán celebrarse contratos para la formación con trabajadores mayores de dieciséis años y menores de veintiún años que carezcan de la titulación requerida para realizar un contrato en prácticas. Pero, como novedad, frente a la inexistencia de límite alguno en la regulación anterior, se ha fijado en 24 años la edad máxima para poder celebrar esta modalidad contractual con desempleados que se incorporen como alumnos/trabajadores a los programas de escuelas taller y casas de oficio. Ahora bien, este límite no será de aplicación cuando el contrato se concierte con desempleados que se incorporen como alumnos-trabajadores a los programas de talleres de empleo ${ }^{64} \mathrm{o}$ se trate de personas con discapacidad.

Ante el silencio guardado por la ley, acerca de la posibilidad de que por medio de los convenios colectivos quepa la posibilidad de modificar estos límites, debe estimarse que nos encontramos ante una norma imperativa absoluta que no admite modificación alguna ${ }^{65}$.

32. Por su parte, entre los colectivos excluidos del ámbito de aplicación se encuentran los trabajadores extranjeros, los trabajadores en situación de exclusión social y los trabajadores que lleven más de tres años sin actividad laboral.

33. Pese a todo, con carácter transitorio, los contratos de trabajo para la formación celebrados con anterioridad al 15 de junio de 2006 (fecha de entrada en vigor del Real Decreto-ley 5/2006) se regirán por la normativa

${ }^{63}$ Estos aspectos han supuesto la modificación del artículo 11.2.a del TRLET por el artículo 12.uno del Real Decreto-ley 5/2006. Esta modificación también se mantiene en la Ley 43/2006.

${ }^{64}$ De todos modos, conforme al Real Decreto 282/1999, de 22 de febrero, por el que se establece el programa de talleres de empleo (BOE de 23 de febrero de 1999, núm. 46), los alumnos-trabajadores en los programas de talleres de empleo no se encuentran sujetos a ningún umbral máximo de edad, pero sí a un tope mínimo, al exigirse veinticinco o más años (artículo 2).

${ }^{65}$ En este sentido, Sempere Navarro, A. V. «Limitaciones a la contratación temporal». In VV. AA. La reforma laboral de 2006. Análisis del Real Decreto-ley 5/2006, de 9 de junio (Sempere Navarro, A. V., Dir.). Pamplona: Aranzadi, monografías Punto de Actualidad, 2006, p. 87. 
legal o convencional vigente en la fecha en que se celebraron (Disposición Transitoria primera de la Ley 43/2006).

34. Como puede apreciarse, la reforma del contrato para la formación resulta muy puntual, y se puede considerar incluso como una contrarreforma respecto a la de 2001. En efecto, tras el Real Decreto-ley 5/2006 parecía haberse perdido nuevamente una gran ocasión para regular en su integridad los contratos formativos y deslindarlos de la figura pre-laboral del becario, con el objetivo de restringir el espacio demasiado amplio que ocupan en la actualidad las zonas grises del Derecho del Trabajo. Sin embargo, el legislador, consciente de la importancia de esta materia, ha reaccionado en la Ley 43/2006, mostrando la voluntad de abordar esta cuestión. En concreto, en la Disposición Adicional décima de la Ley 43/2006, relativa al «empleo de jóvenes», se establece lo siguiente:

«Con el fin de facilitar el empleo de los trabajadores y trabajadores jóvenes, el Gobierno, en el plazo de nueve meses y previo acuerdo con los agentes sociales, presentará medidas encaminadas a regular formas de contratación que optimicen su transición al mercado de trabajo».

Ciertamente, en la actual sociedad, la especialización y la tecnificación en cada uno de los sectores de la productividad atribuyen a la formación una importancia sin precedentes, con lo que resulta necesario una regulación acorde a los nuevos tiempos, que sepa diferenciar las distintas fases y espacios de la formación, y que sirva para cerrar las puertas a la precariedad y a la inestabilidad derivada de su utilización desviada y abusiva entre los jóvenes. En suma, o se apuesta por la formación con calidad y garantías suficientes o la formación no es tal; o se asume la formación como medio para desarrollar la dignidad de las personas o lo único que se consigue es desfigurarlas.

\subsection{La limitación a la concatenación de contratos temporales}

35. Teniendo en cuenta que uno de los mayores males que afecta al mercado de trabajo español es la excesiva utilización de la contratación temporal, la medida que más eco ha tenido en la sociedad, de todas las adoptadas primero en el Real Decreto-ley 5/2006 y después en la Ley 43/2006, ha sido la consistente en limitar la posibilidad de concatenar varios contratos temporales ${ }^{66}$. Claramente, con ello se pretende reducir la temporalidad. El

${ }^{66}$ Tal y como señala GoRELli HeRnÁNDEZ, «el hecho de que se realicen un número tan elevado de contratos temporales... año tras año, evidencia que no hay una verdadera creación de puestos de trabajo, sino que los trabajadores son contratados y vueltos a contratar, para ocupar los mimos puestos de trabajo. Es decir hay una rotación sobre los mismos puestos de trabajo». Es más, este autor concluye afirmando dos datos: por un lado, «se han 
fin de esta medida, en sí, parece saludable, pero habrá que analizar los medios con los que se cuenta para alcanzarlo. Solamente así se podrá valorar el verdadero alcance de la medida adoptada.

36. La verdad es que hasta ahora ha reinado la incertidumbre en esta materia. En principio, se admitía que un empresario celebrase varios contratos temporales sucesivos en el tiempo, con un mismo trabajador -concatenación o encadenamiento de contratos temporales-, o con distintos trabajadores pero para un mismo puesto de trabajo -rotación sobre un mismo puesto de trabajo-. La admisión de estos supuestos requería únicamente la concurrencia en cada supuesto de hecho de la justa causa correspondiente a los contratos temporales celebrados. El problema residía en la dificultad para identificar la justa causa en cada uno de los contratos de trabajo temporales celebrados ${ }^{67}$. Asimismo, con motivo de la abusiva utilización de la contratación temporal se ampliaban las posibilidades de discordancia entre los contratos celebrados y la realidad de los hechos, encubriendo con frecuencia graves supuestos de fraude de ley.

Íntimamente relacionado con todo ello, el TRLET, en su artículo 15.3, define como fraude de ley la contratación temporal fuera de los supuestos establecidos, y si dicho fraude acaece, es decir, si se prueba su existencia, establece la consecuencia jurídica: conversión del contrato temporal en indefinido ${ }^{68}$.

creado unos hábitos entre los empresarios que estiman absolutamente normal la contratación temporal, la rotación continua de diversos trabajadores sobre el mismo puesto de trabajo, el encadenamiento sucesivo de contratos temporales». Por otro lado, «la inestabilidad o precariedad de los trabajadores implica una dualización del mercado de trabajo, condiciones de trabajo diferenciadas (de escasa calidad para los temporales), altas cotas de siniestralidad laboral, nula creación de empleo, etc.» (GoRELLI HERNÁNDEZ, J. «La reforma laboral 2006 y la contratación temporal: la lucha contra el abuso en la contratación temporal. Un análisis de urgencia». In AL, 2006, núm. 17, pp. 2037-2038.

${ }^{67}$ Sobre estos problemas, véase BALLESTER PASTOR, M. A. «La jurisprudencia del TS en torno a la concatenación contractual: declaraciones de principios y quiebras en un contexto de precariedad laboral». In AS, 2000, vol. v, Estudios e Índices, pp. 668-689. En torno a la evolución en España del principio de causalidad en los contratos temporales puede consultarse AguileRa IZQUIERDO, R. «El principio de "causalidad" en la contratación temporal». In RMTAS, 2001, núm. 33, pp. 98-122.

${ }^{68}$ Ante el tenor del artículo 15.3 del TRLET («se presumirán por tiempo indefinido los contratos temporales celebrados en fraude de ley»), hay que entender, con Alonso OlEA y BARREIRo GoNZÁlEZ, que nos encontramos ante una presunción iuris et de iure, puesto que lo que «el precepto nos está queriendo decir es que no nos hallamos ante una presunción, sino en definitiva ante lo que la ley considera per se un fraude, a saber, la celebración de contratos temporales fuera de los casos listados, y ante su reacción contra el mismo al reputarlo celebrado por tiempo indefinido» (Alonso Olea, M. y BARreiro GonZÁlez, G. El Estatuto de los Trabajadores. Texto, Comentarios, Jurisprudencia. Madrid: Civitas, 1995,

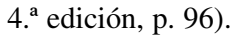


Sin embargo, los problemas se planteaban en la práctica, a la hora de determinar bajo qué circunstancias la sucesión encadenada de contratos temporales constituía un fraude de ley.

Como no podía ser de otra manera, fue la jurisprudencia la que se encargó de fijar los criterios para determinar la falta de causa justa en los correspondientes contratos temporales $\mathrm{y}$, por tanto, la existencia de fraude de ley. Estos criterios dieron lugar a la doctrina jurisprudencial de las interrupciones de veinte días en la cadena de contratos temporales, conforme a la cual en los supuestos de encadenamiento de contratos temporales en los que no existía solución de continuidad entre contratos sucesivos, así como en los que mediasen intervalos de tiempo de inactividad de escasa duración entre contratos, había que entender que detrás de la pluralidad de contratos formalizados subyacía una única relación laboral de carácter indefinido ${ }^{69}$. En ese sentido, la STS, en unificación de doctrina, de 15 de febrero de $2000^{70}$, indicó que «tal solución de continuidad no se produce en la sucesión de contratos temporales cuando entre uno y otro contrato media una interrupción breve, inferior al tiempo de caducidad de la acción de despido [que es de 20 días hábiles]» (Fundamento de Derecho segundo) ${ }^{71}$.

37. Con todo, no se abordaba el problema de raíz. Puesto que era la propia permisibilidad del encadenamiento de contratos temporales, sin límites de duración, la que originaba las dudas sobre la justa causa en la contratación o sobre la existencia de fraude, debía limitarse en el tiempo la concatenación de contratos. Esta medida supondría, igualmente, la reducción de la temporalidad.

Ya no se trataría solamente de luchar contra el fraude de ley, sino que, en una fase previa, se pretendería luchar contra la utilización abusiva del encadenamiento contractual, incluso cuando todos los contratos temporales encadenados resultasen lícitos. Lógicamente, en el supuesto de ilicitud de alguno de los contratos entraría directamente en juego el mecanismo del fraude de ley contemplado en el artículo 15.3 del TRLET.

${ }^{69}$ VV. AA. Manual de Derecho del Trabajo (Molero Manglano, C., Dir.). Madrid: Civitas, 2004, 4. a edición, p. 177.

${ }^{70}$ Ar. 2040.

${ }^{71}$ Véase VALdÉs Alonso, A. «Sucesión de contratos temporales realizados en fraude de ley y determinación del período computable a efectos de la fijación de la indemnización por despido improcedente. Sobre el supuesto carácter presuntivo del artículo 15.3 ET (Comentario a la STS 4. ${ }^{\text {a de } 16}$ de abril de 1999)». In RL, 1999, vol. II, pp. 821-826. Un buen resumen de la evolución de la jurisprudencia del Tribunal Supremo en lo que respecta al fraude de ley en el encadenamiento de contrataciones temporales en Pedrajas Moreno, A., Sala FRANCO, T. y VALDÉs DAL-RE, F. La reforma laboral 2006. Valencia: Tirant lo Blanch, 2006, pp. 54-56. 
38. Precisamente a estas ideas respondió la Directiva 1999/70/CE del Consejo de 28 de junio de 1999, relativa al Acuerdo marco de la CES, la UNICE y el CEEP sobre el trabajo de duración determinada ${ }^{72}$.

Como puede intuirse, esta Directiva tiene su punto de partida en el diálogo social europeo, conforme al cual, las partes contratantes habían manifestado «su deseo de mejorar la calidad del trabajo de duración determinada garantizando la aplicación del principio de no discriminación, y su voluntad de establecer un marco para impedir abusos derivados de la utilización de sucesivos contratos de trabajo de duración determinada o de relaciones laborales de este tipo» (Considerando 14 de la Directiva 1999/70/CE).

Estos objetivos se recogieron en la cláusula 1 del Acuerdo marco sobre trabajo con contrato de duración determinada celebrado el 18 de marzo de 1999 entre las organizaciones interprofesionales de carácter general (UNICE, CEEP y CES), y que, posteriormente, aplica la Directiva 1999/70/CE, tras introducirla en su anexo. De cara a la aplicación de dicho acuerdo, en principio, la Directiva fijó a los Estados miembros la fecha de 10 de julio de 2001, a más tardar, para que pusiesen en vigor las disposiciones legales, reglamentarias y administrativas necesarias (artículo 2).

En concreto, las medidas que debían tener en cuenta los Estados miembros para evitar la utilización abusiva del encadenamiento de contratos temporales se establecieron en la cláusula 5 del Acuerdo.

Así, los Estados miembros, previa consulta con los interlocutores sociales y conforme a la legislación, los acuerdos colectivos y las prácticas nacionales, y/o los interlocutores sociales, y teniendo en cuenta las necesidades de los distintos sectores y/o categorías de trabajadores, debían introducir una o varias de las siguientes medidas, si no contaban con medidas legales equivalentes para prevenir los abusos: a) razones objetivas que justifiquen la renovación de tales contratos o relaciones laborales; b) la duración máxima total de los sucesivos contratos de trabajo o relaciones laborales de duración determinada; c) el número de renovaciones de tales contratos o relaciones laborales.

Igualmente, los Estados miembros, previa consulta a los interlocutores sociales, y/o los interlocutores sociales, cuando resultase necesario, debían determinar en qué condiciones los contratos de trabajo o relaciones laborales de duración determinada se consideran sucesivos, y cuándo se consideran celebrados por tiempo indefinido.

39. En España, la transposición de esta regulación se llevó a cabo mediante la reforma de 2001, incorporando el apartado 5 al artículo 15 del TRLET, según el cual los convenios colectivos podían establecer requisitos dirigidos a prevenir los abusos en la utilización sucesiva de la contratación temporal.

${ }^{72}$ DOUE de 10 de julio de 1999, núm. L 175. 
Esta disposición merece la calificación de vaga en todos los sentidos, puesto que, además de no apostar por ninguna de las medidas propuestas por la Directiva 1999/70/CE, dejaba en manos de la negociación colectiva una cuestión de máximo interés para luchar contra la temporalidad. Una decisión incomprensible cuando la reforma perseguía supuestamente el incremento del empleo y la mejora de su calidad.

40. Finalmente, han sido el Real Decreto-ley 5/2006 y la Ley 43/2006 las normas que, tras modificar el apartado 5 del artículo 15 del TRLET, han transpuesto adecuadamente la Directiva 1999/70/CE, al apostar decididamente por una de las medidas propuestas en ella, a saber, la concreción de la duración máxima total de los sucesivos contratos de trabajo o relaciones de duración determinada. Por tanto, es justo reconocer el avance social que esta medida puede suponer, en aras de la estabilidad en el empleo y a su calidad, pero también es preciso analizar los principales aspectos de la nueva medida, puesto que de su elaboración e interpretación depende el éxito de la apuesta realizada.

41. En realidad, en la nueva regulación se diferencian dos instituciones: la concatenación o encadenamiento de contratos temporales y la rotación sobre un mismo puesto de trabajo. Pero el esfuerzo normativo ha recaído sobre la primera de las instituciones. Además, conviene tener presente que, sin justificación alguna, el legislador ha excluido expresamente del ámbito de aplicación de estas dos instituciones a los contratos formativos, de relevo e interinidad (párrafo tercero del nuevo apartado 5 del artículo 15 del TRLET).

En relación con el fenómeno de la rotación sobre un mismo puesto de trabajo, como única novedad, supuestamente se ha reforzado la antigua posibilidad de establecer requisitos en los convenios colectivos para prevenir los abusos en la utilización sucesiva de la contratación temporal. A tal efecto, se establece lo siguiente:

«Atendiendo a las peculiaridades de cada actividad y a las características del puesto de trabajo, la negociación colectiva establecerá requisitos dirigidos a prevenir la utilización abusiva de contratos de duración determinada con distintos trabajadores para desempeñar el mismo puesto de trabajo cubierto anteriormente con contratos de ese carácter, con o sin solución de continuidad, incluidos los contratos de puesta a disposición realizados con empresas de trabajo temporal» (párrafo segundo del nuevo apartado 5 del artículo 15 del TRLET).

De ello puede extraerse que en la actualidad existe una obligación, un imperativo de negociar dichos requisitos. Lo que sucede es que no se ha aprovechado la ocasión para introducir esta cuestión dentro del contenido mínimo que han de tener los convenios colectivos según el artículo 85.3 del 
TRLET. Así pues, hubiese resultado coherente la modificación de dicho precepto en ese sentido ${ }^{73}$.

Por otra parte, al remitirse esta materia a la negociación colectiva, nada debería impedir la posibilidad de computar, a los efectos de esta institución, también los contratos formativos, de relevo e interinidad, pese haber sido excluidos en este ámbito por el legislador. Con lo que cabría la posibilidad de ir más allá de lo realmente querido por el legislador ${ }^{74}$.

Lo que sucede es que el legislador no da ninguna pista acerca de los requisitos que pueden establecerse en la negociación, con lo que se exige el esfuerzo imaginativo de las partes negociadoras ${ }^{75}$. El mandato que tenía que establecer tales requisitos debería haber sido más amplio y más intenso.

42. En lo que respecta a la regulación de la concatenación o encadenamiento de contratos temporales, donde se introducen las novedades más relevantes, el legislador, en primer lugar, parece que quiere dejar claro que con esta medida no se altera lo establecido en los apartados 2 y 3 del artículo 15 del TRLET -«sin perjuicio de lo dispuesto en los apartados 2 y $3 \ldots »-$.

Muy al contrario, la nueva medida viene a complementar las establecidas por dichos apartados, con lo que en el futuro deberá realizarse una interpretación teleológica y de conjunto de todos estos preceptos. Efectivamente, el objetivo del nuevo apartado 5 del artículo 15 del TRLET no es sancionar ciertos incumplimientos o el fraude de ley, pues a ese fin responden los apartados 2 y 3; el nuevo aparatado 5 se dirige a prevenir el uso abusivo de la sucesión de contratos temporales que venía realizándose con la anterior normativa, y que resultaba propicia para aumentar los incumplimientos y los supuestos de fraude de ley.

Una vez realizada esa matización, se introduce la medida concreta para limitar la concatenación o encadenamiento de contratos temporales, según la cual...

«... los trabajadores que en un período de treinta meses hubieran estado contratados durante un plazo superior a veinticuatro meses, con o sin solución de continuidad, para el mismo puesto de trabajo con la misma empresa, mediante dos o más contratos temporales, sea directamente o a través de su puesta a disposición por empresas de trabajo temporal, con las mismas o diferentes modalidades contractuales de duración determinada,

${ }^{73}$ Vid. LAHERA ForTEZA, J. «Límites novedosos en el encadenamiento de contratos temporales». In VV. AA. La Reforma Laboral de 2006. Real Decreto Ley 5/2006, de 9 de junio (CruZ Villalón, J., Coord.). Valladolid: Lex Nova, 2006, pp. 67-69.

${ }^{74}$ Sempere Navarro, A.V. «Limitaciones a la contratación temporal». In VV. AA. La reforma laboral de 2006. Análisis del Real Decreto-ley 5/2006, de 9 de junio (SEMPERE Navarro, A.V., Dir.). Pamplona: Aranzadi, monografías Punto de Actualidad, 2006, p. 121.

${ }^{75}$ Así lo entiende TASCÓN LÓPEZ, quien aporta, además, posibles soluciones (TASCÓN LÓPEZ, R. ob. cit., pp. 96-98). 
adquirirán la condición de trabajadores fijos» (párrafo primero del nuevo apartado 5 del artículo 15 del TRLET) ${ }^{76}$.

La multitud de requisitos que contiene esta medida hace imprescindible el tratamiento de cada uno de ellos. Es más, a la luz de dicho tratamiento podrá valorarse el verdadero alcance de esta medida.

43. En primer lugar, es necesario que se produzca un encadenamiento de «dos o más contratos temporales».

A efectos transitorios, conforme a la Disposición Transitoria segunda de la Ley 43/2006, la medida para limitar la concatenación o encadenamiento de contratos temporales será de aplicación a los trabajadores que suscriban tales contratos a partir del 15 de junio de 2006 (fecha de entrada en vigor del Real Decreto-ley 5/2006), pero también hay que tener en cuenta que para computar los contratos encadenados se considerará primer contrato el suscrito por el trabajador con anterioridad al 15 de junio de 2006 y que siga vigente tras esa fecha.

A través de este requisito es cierto que se avanza en la consecución de la estabilidad en el empleo. También es cierto que se limita el abuso en la contratación temporal sucesiva, y que gracias a ello disminuye la posibilidad de incumplimientos y de fraude de ley que conducen a la precariedad laboral. Ello no obstante, al quedar fuera del supuesto de hecho la celebración de una sola contratación, los abusos se cometerán en forma de contratos temporales de larga duración, y más concretamente en los contratos de obra o servicio determinado. Especial atención merece el sector de la construcción, en el que a través de figuras como la del fijo de obra seguirá siendo posible celebrar un único contrato de obra con un trabajador aunque, en realidad, éste realice sucesivamente distintas obras, sin necesidad de celebrar nuevos contra$\operatorname{tos}^{77}$. La situación se agrava cuando los contratos de obra o servicio se incar-

${ }^{76}$ El Real Decreto-ley 5/2006 y la Ley 43/2006, tras modificar el contenido de la Disposición Adicional 15 del TRLET, lo extienden también al ámbito de las Administraciones públicas y sus organismos autónomos, «sin perjuicio de la aplicación de los principios constitucionales de igualdad, mérito y capacidad en el acceso al empleo público, por lo que no será obstáculo para la obligación de proceder a la cobertura de los puestos de trabajo de que se trata a través de los procedimientos ordinarios, de acuerdo con lo establecido en la normativa aplicable» (artículo 12.Trece).

77 Al respecto, véase Sempere Navarro, A.V. «Contratación como fijo de obra para varias edificaciones indeterminadas. Comentario a la STS de 30 de junio de 2005». In Aranzadi, Repertorio de Jurisprudencia, 2005, vol. vII, Estudios, núm. 46, pp. 21737-21747. Para el estudio detallado del contrato fijo de obra pueden consultarse VV. AA. La negociación colectiva en el sector de la construcción. Madrid: Ministerio de Trabajo y Asuntos Sociales, 2002, pp. 101-106. Igualmente, resulta muy interesante desde el punto de vista del análisis normativo y jurisprudencial de esta figura contractual MolTó GARCíA, J. I. Relaciones laborales en el sector de la construcción. El convenio general del sector. Valencia: CISSPRAXIS, 2000, pp. 92-103. 
dinan en las relaciones derivadas de contratas y subcontratas. Como botón de muestra, cuando, en los supuestos de sucesión de contratas, el contratista utiliza los mismos trabajadores para llevar a cabo una serie de obras o servicios distintos para el mismo empresario principal o comitente, la jurisprudencia de unificación ha considerado que no tiene por qué existir una pluralidad de contratos de obra o servicio, sino que cabe una novación contractual que extienda sus efectos a las nuevas contratas ${ }^{78}$. Por lo tanto, de mantenerse esta jurisprudencia, resultará inaplicable el artículo 15.5 del TRLET. Paradójicamente, lo que antes parecía defenderse en nombre de la estabilidad en el empleo, ahora se torna en contra de las medidas establecidas para impedir la temporalidad ${ }^{79}$. Por último, lo más preocupante es que no parezca que el legislador tenga la intención de abordar estas cuestiones. Así lo demuestra la reciente Ley 32/2006, de 18 de octubre, reguladora de la subcontratación en el Sector de la Construcción ${ }^{80}$, al señalar esto:

«... la negociación colectiva de ámbito estatal del sector de la construcción podrá adaptar la modalidad contractual del contrato de obra o servicio determinado prevista con carácter general mediante fórmulas que garanticen mayor estabilidad en el empleo de los trabajadores, en términos análogos a los actualmente regulados en dicho ámbito de negociación» (Disposición Adicional tercera. Negociación colectiva y calidad en el empleo).

En resumen, aunque de manera imprecisa y ambigua, en el sector de la construcción se da continuidad a aquellas figuras y prácticas que, como se ha observado, quedan fuera del supuesto de hecho del artículo 15.5 del TRLET.

44. En segundo lugar, hay que tener en cuenta que computa cualquier modalidad de contrato temporal, excepto los contratos formativos, de relevo e interinidad. Además, el empresario que opta por la contratación temporal, podrá llevarla a cabo «directamente» o a través de la puesta a disposición de los correspondientes trabajadores por las empresas de trabajo temporal. Estas cuestiones plantean una serie de dudas.

Respecto a la exclusión del cómputo de los contratos formativos, de relevo e interinidad, surge la duda en los casos en que dentro del encadenamiento de diversos contratos temporales se intercale alguno de esos contratos exceptuados. Ciertamente, las soluciones son $\operatorname{dos}^{81}$ : o se entiende que los

\footnotetext{
${ }^{78}$ Se refiere a esta posibilidad, entre otras, la STS, en unificación de doctrina, de 22 de octubre de 2003 (Ar. 8390), en su quinto Fundamento de Derecho.

${ }^{79}$ Véase SEMPERE NAVARRO, A.V. «Limitaciones a la contratación temporal». In VV. AA. La reforma laboral de 2006. Análisis del Real Decreto-ley 5/2006, de 9 de junio (SEMPERE NAVARRO, A.V., Dir.). Pamplona: Aranzadi, monografías Punto de Actualidad, 2006, pp. 109-110.

${ }^{80}$ BOE de 19 de octubre de 2006, núm. 250.

${ }^{81}$ Sobre esta misma duda se pronuncia GoRELLi HeRnÁnDEZ, J. «La reforma laboral 2006 y la contratación temporal: la lucha contra el abuso en la contratación temporal. Un análisis de urgencia». In AL, 2006, núm. 17, p. 2046.
} 
contratos exceptuados interrumpen el cómputo y, en consecuencia, dan lugar al inicio de otro plazo distinto; o se entiende que los contratos exceptuados suspenden el cómputo y, por ende, suponen una especie de «tiempo muerto», que no impide, una vez finalizado éste, «mantener vivo» el plazo iniciado con anterioridad. Desde el punto de vista teleológico de la norma, a saber, la eliminación de la precariedad laboral y, para conseguir dicho fin, la limitación a la concatenación abusiva y desproporcionada de la contratación temporal, parece razonable optar por la segunda de las soluciones.

En cuanto a las posibilidades del empresario de contratar temporalmente de manera indirecta, a través de una empresa de trabajo temporal, hay que estar al sentido literal de la redacción del precepto, para concluir que la consecuencia del precepto, a saber, la conversión a fijo del trabajador temporal, operará siempre en la empresa usuaria. Analógicamente, puede traerse a colación lo establecido por el artículo 7.2 de la Ley 14/1994, de 1 de junio, por la que se regulan las empresas de trabajo temporal (LETT) ${ }^{82}$. Así, conforme a ese precepto...

«Si a la finalización del plazo de puesta a disposición el trabajador continuara prestando servicios en la empresa usuaria, se le considerará vinculado a la misma por un contrato indefinido».

Por su parte, la toma en consideración, a efectos del artículo 15.5 del TRLET, de la contratación indirecta a través de empresas de trabajo temporal ha supuesto la derogación tácita del segundo inciso del artículo 8.c de la LETT (artículo 13 del Real Decreto-ley 5/2006 y de la Ley 43/2006). Conviene recordar que, conforme a dicho precepto, se impedía a las empresas recurrir a la contratación indirecta cuando en los dieciocho meses anteriores a dicha contratación los puestos de trabajo en cuestión hubieran estado cubiertos durante un período de tiempo superior a doces meses, de forma continua o discontinua, por trabajadores puestos a disposición por empresas de trabajo temporal.

La derogación de este inciso debe calificarse de errónea, pues aunque el artículo 15.5 del TRLET resulte más favorable para los trabajadores en el supuesto de la concatenación, se deja de frenar la rotación de trabajadores en misión en un mismo puesto. Por ello, debe estimarse que «no era inevitable la supresión del precepto» ${ }^{83}$.

45. En tercer lugar, la duración del período en el que los trabajadores deben prestar sus servicios para el mismo empresario mediante el encadenamiento de dos o más contratos temporales debe ser «superior a veinticuatro meses», dentro de «un período de treinta meses».

${ }^{82}$ BOE de 2 de junio de 1994, núm. 131.

${ }^{83}$ LAHERA ForTEZA, J. ob. cit, p. 55. 
La primera duda que plantea este requisito se relaciona con los efectos transitorios regulados en la propia Ley 43/2006 para con los contratos temporales suscritos con anterioridad al 15 de junio de 2006 (fecha de entrada en vigor del Real Decreto-ley 5/2006) pero que siguen vigentes tras esa fecha.

Del segundo párrafo de la Disposición Transitoria segunda de la Ley 43/2006 se deduce claramente que estos contratos se tendrán en cuenta a los efectos del cómputo del numero de contratos concatenados. En suma, estos contratos deberán computarse como los primeros en la cadena, y no parece que haya nada que objetar a esta disposición, pues dichos contratos siguen vigentes con la nueva normativa.

Sin embargo, la duda que oscurece dicha claridad se cierne sobre el mutismo del legislador, en relación con la toma en consideración o no de la duración del contrato celebrado con anterioridad al 15 de junio de 2006, y que sigue vigente tras esa fecha, a efectos de sumar los veinticuatro meses dentro del plazo de treinta.

Por ende, la duda consiste en determinar si la duración de dicho contrato debe tenerse en cuenta desde el momento de su celebración o solamente desde el 15 de junio de 2006.

La respuesta a esta duda pasa por la interpretación del primer párrafo de la Disposición Transitoria segunda de la Ley 43/2006, según la cual los efectos del artículo 15.5 del TRLET deben proyectarse únicamente en los trabajadores que suscriban contratos temporales a partir del 15 de junio de 2006 .

Tal y como puede apreciarse, son dos los elementos clave para la efectividad de los efectos del artículo 15.5 del TRLET: en primer lugar, la toma en consideración de la fecha de 15 de junio de 2006 y, en segundo lugar, la celebración de contratos temporales con posterioridad a dicha fecha.

Lo que sucede es que, en los casos en los que con anterioridad al 15 de junio de 2006 el trabajador cuente ya con un contrato de trabajo temporal, el tiempo que transcurre desde el 15 de junio de 2006 hasta la extinción de ese contrato se equipara a la duración de un contrato celebrado con posterioridad al 15 de junio de 2006. Además, este planteamiento encaja a la perfección con la idea según la cual el contrato celebrado con anterioridad al 15 de junio de 2006 debe computar como el primero en la cadena, cuando dicho contrato siga vigente tras dicha fecha.

De acuerdo con estos planteamientos, cabe señalar, igualmente, que los efectos del artículo 15.5 son a futuro, a partir del 15 de junio de 2006, por lo que no cabe hablar de retroactividad. Además, tampoco debe olvidarse que la legislación laboral y de Seguridad Social, ciertamente, no acoge la regla de la retroactividad. Con frecuencia se habla de retroactividad de grado mínimo o in mitius, cuando la nueva ley sólo se aplica a los efectos que tengan lugar tras su entrada en vigor, a pesar de que traigan su origen en una relación jurídica nacida al amparo de la ley derogada, pero tampoco en esos 
casos existe verdadera retroactividad, porque la nueva ley se aplica a los efectos futuros ${ }^{84}$.

En consecuencia, para computar los veinticuatro meses en un plazo de treinta, solamente deberá tenerse en cuenta, respecto al contrato celebrado con anterioridad al 15 de junio de 2006, el tiempo transcurrido a partir de esa fecha.

Por otro lado, también parece criticable que se establezca el criterio del doble período, puesto que con ello puede quedar sin aplicación el artículo 15.5 del TRLET tan sólo con evitar la superación de los veinticuatro meses. Así, no se producirá la conversión en fijo en aquellos supuestos en los que se concatenen contratos de menor o igual duración a los veinticuatro meses. Por ese motivo, hubiera sido preferible apostar por una fórmula mixta, conforme a la cual se tuviesen en cuenta dos de las tres opciones señaladas por la Directiva 1999/70/CE: el hecho de que un empresario celebre sucesivamente un número determinado de contratos temporales con un mismo trabajador y la regulación de un determinado tope de duración ${ }^{85}$.

En cambio, el cómputo de los treinta meses no parece que pueda crear problemas, puesto que, a pesar del silencio normativo, debe entenderse, conforme al artículo 5 del Código Civil, de carácter general subsidiario, que los treinta meses han de ser consecutivos, de fecha a fecha, sin posibilidad de suspensión e interrupción ${ }^{86}$.

46. En cuarto lugar, la posibilidad de que los veinticuatro meses se computen «con o sin solución de continuidad», echa por tierra la doctrina jurisprudencial de las interrupciones de veinte días en la cadena de contratos temporales (supra 3.3, 36).

47. En quinto lugar, el hecho de que la contratación debe ser «para el mismo puesto de trabajo con la misma empresa» supone un margen demasiado amplio para «burlar» la operatividad del artículo 15.5 del TRLET.

${ }^{84}$ Véase Rivero Lamas, J. y De Val Tena, A. «Retroactividad». In Diccionario Jurídico Laboral (Ojeda Aviles, A. y Gorelli Hernández, J., Coord.). Granada: Comares, 1999, pp. 592-593. Igualmente, consúltese Villar Palasi, J. L. y SuÑE Llinas, E. «Artículo 9. El Estado de Derecho y la Constitución». In Comentarios a la Constitución Española de 1978 (Alzaga Villaamil, O., Dir.). Madrid: Editoriales de Derecho Reunidas, 1996, tomo I, Preámbulo y artículos 1 a 9, pp. 563-566. Refiriéndose, básicamente, a la Seguridad Social, véase VV. AA. Curso de Derecho del Trabajo (RAmírez MartíneZ, J. M., Dir.). Valencia: Tirant lo Blach, 2006, edición 15. a , pp. 48-49.

${ }^{85}$ Defendiendo esta postura, vid. Gorelli Hernández, J. «La reforma laboral 2006 y la contratación temporal: la lucha contra el abuso en la contratación temporal. Un análisis de urgencia». In AL, 2006, núm. 17, p. 2043.

${ }^{86}$ Véase Cabanillas Sánchez, A. Comentarios al Código Civil y compilaciones forales (Albaladejo, M. y Díaz Alabart, S., Dir.). Artículo 5, tomo I, vol. I, artículos 1 a 7 del Código Civil. Madrid: Editorial Revista de Derecho Privado, 1992, pp. 623-658. 
Tal es así, que la estricta y rígida referencia al «puesto de trabajo» posibilita la contratación del mismo trabajador, con una mera modificación funcional, dentro del mismo grupo profesional o entre categorías profesionales equivalentes. Increíblemente, en este supuesto, el legislador no ha tenido en cuenta la actual organización de la empresa.

El requisito según el cual el contrato debe celebrarse «con la misma empresa» también dará lugar a muchos problemas de interpretación, porque el legislador se aleja de la realidad imperante de la descentralización productiva, en la que el trabajador presta sus servicios para diversas empresas.

Especialmente, de nuevo se echa en falta una regulación que aborde con garantías el fenómeno de los grupos de empresas, por lo que en los supuestos en los que sea posible habrá que seguir aplicando la jurisprudencia del «levantamiento del velo de la personalidad jurídica».

Por el contrario, en los casos de sucesión de empresa, conforme al artículo 44 del TRLET, el nuevo empresario quedaría subrogado en los derechos y obligaciones laborales del anterior, y, por tanto, los trabajadores tendrían derecho a continuar el cómputo de sus contratos temporales celebrados con el anterior empresario. Partiendo de dicha afirmación, más difícil resultará, sin duda, dilucidar los supuestos de sucesión de contratas de obras y servi$\operatorname{cios}^{87}$, para determinar en qué empresa adquiere el trabajador el carácter de fijo.

48. En sexto lugar, en torno a la consecuencia del supuesto de hecho contemplado en el artículo 15.5 del TRLET, según la cual los trabajadores «adquirirán la condición de trabajadores fijos», el problema reside en la no especificación de la naturaleza de dicha fijeza.

La solución puede consistir en acudir analógicamente a alguna de las dos opciones que contempla el TRLET para supuestos similares ${ }^{88}$. Por un lado, considerar la relación jurídica laboral indefinida y a tiempo completo, tal y como se determina, por ejemplo, en el artículo 8.2. Por otro lado, entender que los derechos y obligaciones del trabajador que ha adquirido la condición de fijo serán los que «correspondan en condiciones ordinarias a un trabajador que preste servicios en el mismo o equivalente puesto de trabajo» tal y como se establece en el artículo 43.4 del TRLET, en los casos de cesión ilegal en los que el trabajador afectado decide adquirir la condición de fijo en la cesionaria. Con todo, teniendo en cuenta la gran variedad de sectores productivos, así como sus especificidades, parece más razonable apostar por la segunda opción.

${ }^{87} \mathrm{Al}$ respecto véase Pedrajas Moreno, P. y Sala Franco, T. Contratas y empresas de trabajo temporal: responsabilidades. Valencia: Tirant lo Blach, 2006, pp. 59-82.

${ }^{88}$ TASCÓN LÓPEZ, R. ob. cit., pp. 92-93. 


\subsection{Medidas adoptadas para mejorar la transparencia en la subcontrata-} ción de obras y servicios y su delimitación respecto de la cesión ilegal de trabajadores

49. En este ámbito, pese a su importancia, las novedades no son muy relevantes. Como se observará, no se han abordado cuestiones de máximo interés que seguirán creando problemas de interpretación. En consecuencia, la reforma supone un nuevo «parcheo», cuando en realidad se requiere una regulación acorde a la realidad.

50. Así, en materia de contratas y subcontratas, la reforma se ha limitado a regular una serie de derechos de información, representación y reunión de los representantes de los trabajadores. Por el contrario, no se ha avanzado en los dos aspectos que, a priori, tal y como se deduce del Documento para la mesa de diálogo social sobre mercado de trabajo, de 18 de octubre de 2005, tenían más urgencia para salvaguardar los derechos de los trabajadores: la definición de los conceptos del artículo 42 del TRLET (empresario principal, empresario contratista, empresario subcontratista, contrato de obras y servicios, propia actividad) ${ }^{89}$ y la reelaboración de la teoría de las responsabilidades empresariales en esta materia.

51. De este modo, permanece incólume el contenido del artículo 42 del TRLET, en lo que respecta a la delimitación del supuesto de hecho y a las obligaciones y responsabilidades básicas de los empresarios. Las novedades se circunscriben al ámbito colectivo, pues se reconocen nuevos derechos de información, representación y reunión a los representantes legales de los trabajadores, en aquellos casos en que los trabajadores de la empresa principal, de la contratista o subcontratista desarrollan su actividad de forma continua$\mathrm{da}^{90}$ en un mismo centro de trabajo ${ }^{91}$. En concreto, son tres las medidas que se han adoptado.

\footnotetext{
${ }^{89}$ En cambio, la Ley 32/2006, de 18 de octubre, reguladora de la subcontratación en el sector de la construcción sí ha procedido a la definición, a efectos de su ámbito de aplicación, de los conceptos de obra de construcción u obra, promotor, dirección facultativa, coordinador en materia de seguridad y salud durante la ejecución de la obra, contratista o empresario principal, subcontratista, trabajador autónomo, subcontratación y nivel de subcontratación (artículo 3).

${ }^{90} \mathrm{La}$ expresión «continuada» resulta demasiado inespecífica, por lo que no es de extrañar que surjan problemas interpretativos sobre su verdadero alcance. Sería conveniente entender dicha expresión como ininterrumpida, con el objetivo de dar cabida a las contratas o subcontratas de breve duración.

${ }^{91}$ Resulta conveniente, de cara a la efectividad de la norma, entender en sentido amplio el concepto «centro de trabajo», y no identificarlo con el artículo 1.5 del TRLET. Así, conforme a una interpretación amplia, se supera la idea de un espacio físico determinado.
} 
52. En primer lugar, con el objeto de facilitar la coordinación de la acción de los representantes de los trabajadores afectados por el régimen de contratación y subcontratación, el empresario principal deberá disponer de un libro registro en el que se refleje, respecto a todas las empresas implicadas en el proceso de contratación y subcontratación, la misma información que dicho empresario debe suministrar a los representantes legales de sus trabajadores en casos de contratas y subcontratas. Además, el libro registro estará a disposición de los representantes legales de los trabajadores de todas las empresas implicadas en la cadena de contratas y subcontratas ${ }^{92}$ (esta medida ha supuesto la incorporación de un último párrafo en el apartado 4 del artículo 42 del TRLET).

Consecuentemente con esta medida, el artículo 14 del Real Decreto-ley 5/2006 y de la Ley 43/2006 ha añadido un nuevo apartado 12 al artículo 7 del texto refundido de la Ley sobre infracciones y sanciones en el orden social, aprobado por el Real Decreto Legislativo 5/2000, de 4 de agosto ${ }^{93}$, con el fin de considerar infracción grave la no disposición por parte de las empresas principales del libro registro de las empresas contratista o subcontratistas a que se refiere el artículo 42.4 del TRLET, cuando ello comporte la ausencia de información a los representantes legales de los trabajadores.

53. En segundo lugar, con la finalidad de proteger con más garantías los derechos e intereses de los trabajadores de las empresas contratistas y subcontratistas, se reconoce a éstos el derecho a formular a los representantes de los trabajadores de la empresa principal cuestiones relativas a las condiciones de ejecución de la actividad laboral. No obstante, para ejercitar este derecho es necesario que los trabajadores de las empresas contratistas y subcontratistas carezcan de representación legal ${ }^{94}$. Igualmente, se matiza que dichos trabajadores no podrán plantear reclamaciones referidas a la empresa de la que dependen ante los representantes legales de la empresa principal (esta medida ha supuesto la incorporación de un nuevo apartado 7 al artículo 42 del TRLET).

Ahora bien, el hecho de que los trabajadores de las empresas contratistas y subcontratistas sólo puedan formular ante los representantes de los trabajadores de la empresa principal cuestiones relacionadas con las condiciones de ejecución de la actividad laboral, además de limitado parece incon-

\footnotetext{
${ }^{92} \mathrm{Al}$ respecto, véase Sempere NAVARro, A.V. «Los fenómenos interempresariales y el nuevo Libro registro tras el Real Decreto-ley 5/2006: un esquema». In AS, 2006, núm. 7-8, pp. 14-19.

${ }^{93}$ BOE de 8 de agosto de 2000, núm. 189.

${ }^{94}$ Sobre esta particular situación véase ÁlvVAREZ CUESTA, H. «Subcontratación de obras y servicios». In Aspectos puntuales de la Reforma Laboral de 2006. Análisis del Real Decreto-ley 5/2006 (Fernández DomíngueZ, J. J., Dir. y Coord.). Murcia: Ediciones Laborum, 2006, pp. 135-141.
} 
gruente. La regulación resulta limitada porque quedan fuera de la posibilidad de consulta aspectos tan importantes como los relativos a la seguridad e higiene en el trabajo. Por su parte, la incongruencia deriva del hecho de que, en realidad, la empresa principal debería preocuparse por la seguridad e higiene en el trabajo, y no por las condiciones de su ejecución, pues las facultades de organización y dirección de los servicios laborales corresponden a la empresa contratista o subcontratista. En definitiva, con la regulación de esta medida se introduce en el ámbito de las contratas y subcontratas un indicio de cesión ilegal, y con ello difícilmente pueden delimitarse, tal y como se propone la reforma, las contratas y subcontratas respecto a las cesiones ilegales de trabajadores ${ }^{95}$.

54. En tercer lugar, también con el fin de facilitar la coordinación entre los representantes de los trabajadores de la empresa principal y los de las empresas contratistas y subcontratistas, en relación con las condiciones de ejecución de la actividad laboral, se reconoce el derecho a reunión conjunta de todos los representantes legales implicados en el proceso de contratación y subcontratación. En relación con ese derecho, se reconoce a dichos representantes, igualmente, el uso de los locales que los representantes unitarios de la empresa principal utilizan para desarrollar sus actividades y comunicarse con los trabajadores. Ahora bien, el uso de dichos locales deberá realizarse en los términos acordados con la empresa principal (esta medida ha supuesto la incorporación de un nuevo apartado 7 al artículo 42 del TRLET, así como la modificación del artículo 81 del TRLET).

Nuevamente, es criticable que se relacione a la empresa principal con cuestiones relativas a la organización y dirección de los servicios laborales prestados por los trabajadores pertenecientes a contratas y subcontratas.

55. Con la finalidad de deslindar las contratas y subcontratas de la cesión ilegal de los trabajadores, es cierto que la reforma ha apostado por dar una definición de cesión ilegal. De este modo, se satisface la reclamación que al respecto venía realizando la doctrina ${ }^{96}$. Pero, en realidad, la reforma se ha limitado a recoger los principales indicios de necesaria presencia que ha elaborado la jurisprudencia para poder constatar la existencia de una contrata o de una cesión ilegal. Ciertamente, tales indicios constituyen criterios de valoración de la realidad totalmente válidos, pero no puede entenderse que la definición de cesión ilegal se centre únicamente en ellos. Muy al contrario, la causística existente, al respecto, evidencia que se trata de una definición ejemplarizante y, por tanto, númerus apertus. De forma y manera que la jurisprudencia continuará

95 Pedrajas Moreno, A., Sala Franco, T. y Valdés Dal-Re, F. La reforma laboral 2006. Valencia: Tirant lo Blanch, 2006, p. 27.

${ }^{96}$ Por todos, Pedrajas Moreno, P. y Sala Franco, T. Contratas y empresas de trabajo temporal: responsabilidades. Valencia: Tirant lo Blach, 2006, p. 17. 
elaborando interesantes indicios a tener en cuenta. Además, los indicios recogidos por la reforma requieren una aplicación ponderada, y aunque no tienen por qué concurrir acumulativamente, tampoco son excluyentes; más bien son complementarios. Igualmente, para interpretar tales indicios será imprescindible la toma en consideración de la jurisprudencia existente al respecto.

56. Así, la reforma ha supuesto la modificación del artículo 43 del TRLET. Concretamente, la definición de cesión ilegal se recoge en el apartado 2, de la siguiente manera:

«En todo caso, se entiende que se incurre en cesión ilegal de trabajadores... cuando se produzca alguna de las siguientes circunstancias: que el objeto de los contratos de servicios entre las empresas se limite a una mera puesta a disposición de los trabajadores de la empresa cedente a la empresa cesionaria, o que la empresa cedente carezca de una actividad o de una organización propia y estable, o no cuente con los medios necesarios para el desarrollo de su actividad, o no ejerza las funciones inherentes a su condición de empresario».

\section{Medidas adoptadas para mejorar la protección de los trabajadores ante la falta de empleo y para potenciar políticas activas de empleo}

57. Por último, tanto el Real Decreto-ley 5/2006 como la Ley 43/2006 establecen de manera un tanto desordenada, a lo largo de su articulado, una serie de medidas con la doble intención de mejorar la protección de los trabajadores ante la falta de empleo y de potenciar políticas activas de empleo. Estas medidas afectan al Fondo de Garantía Salarial (FOGASA), a la protección por desempleo de colectivos específicos, y a la mejora de los servicios públicos en el mercado de trabajo. A las principales características de tales medidas nos referiremos a continuación.

\subsection{Las medidas adoptadas respecto al Fondo de Garantía Salarial}

58. La situación de superávit que presenta el FOGASA desde el año 2000 ha supuesto la modificación del artículo 33 del TRLET por parte del Real Decreto-ley 5/2006, y la asunción de dicha modificación por la Ley $43 / 2006$, con la finalidad de mejorar la protección de los trabajadores dispensada por el FOGASA en caso de insolvencia empresarial ${ }^{97}$.

${ }^{97}$ Véase De La Puebla Pinilla, A. y Pérez Yánez, R. «El Acuerdo para la mejora del crecimiento y del empleo de 9 de mayo de 2006, ¿una mínima reforma o una reforma de mínimos?» In RL, 2006, núm. 12, pp. 63-65. Respecto a las mejoras que supone la reforma en torno al FOGASA, CAVAS MARTíneZ, F. «Mejoras en la protección del FOGASA tras el Real Decreto-ley 5/2006». In AS, 2006, núm. 9, pp. 9-22. 
59. La mejora de la protección se aprecia, en primer lugar, respecto a los salarios adeudados a los trabajadores en casos de insolvencia empresarial, para lo que se ha modificado el artículo 33.1 del TRLET.

Así, se ha ampliado, como primer tope, la cuantía máxima del salario que abona el FOGASA, pasándose del duplo del salario mínimo interprofesional diario al triple. Además, tras la reforma, se incluye la parte proporcional de las pagas extraordinarias en el módulo del salario mínimo interprofesional utilizado para cuantificar el límite de la responsabilidad por salarios a cargo del FOGASA.

Del mismo modo, respecto al segundo tope, se ha aumentado de 120 a 150 el número de días máximos de salario pendiente de pago a abonar por el FOGASA.

60. En segundo lugar, se mejora la protección por el FOGASA de las indemnizaciones reconocidas por despido, extinción o finalización de contratos, para lo que se ha modificado el artículo 33.2 del TRLET.

La modificación ha supuesto, en este sentido, la introducción de las siguientes novedades:

a) El salario diario máximo, base del cálculo de la indemnización, se amplia del duplo del salario mínimo interprofesional al triple.

b) El importe de la indemnización, a los solos efectos de abono por el FOGASA para los casos de despido o extinción de los contratos conforme al artículo 50 del TRLET, se calculará sobre la base de 30 días por año de servicio, frente a los 25 días anteriores, respetando el límite máximo de una anualidad.

c) Se incluyen entre las indemnizaciones protegidas por el FOGASA las debidas a la extinción por todas las causas objetivas previstas en el artículo 52 del TRLET. Con anterioridad a la reforma, solamente se protegían las indemnizaciones debidas como consecuencia del despido objetivo por causas económicas, técnicas, organizativas o de producción.

d) Se incluyen entre las indemnizaciones protegidas por el FOGASA las debidas por extinción del contrato de conformidad con el artículo 64 de la Ley 22/2003, de 9 de julio, Concursal ${ }^{98}$.

e) Se incluyen entre las indemnizaciones protegidas por el FOGASA las debidas por finalización de los contratos temporales.

f) Se incluyen entre las indemnizaciones protegidas por el FOGASA las debidas por conciliación judicial. Además, parece promoverse una mayor participación de los representantes del FOGASA en dichas

${ }^{98}$ BOE de 10 de julio de 2003, núm. 164. 
conciliaciones, según se deduce del Acuerdo para la mejora del crecimiento y del empleo, de 9 de mayo de 2006. En cambio, con anterioridad a la reforma, solamente se incluía entre las indemnizaciones protegidas las reconocidas como consecuencia de sentencia o resolución administrativa a favor de los trabajadores.

61. En tercer lugar, en el artículo 33.8 del TRLET, relativo a la protección por el FOGASA en las empresas de menos de veinticinco trabajadores, se incluyen entre las indemnizaciones protegidas, las debidas a la extinción del contrato de trabajo en virtud del artículo 64 de la Ley 22/2003, de 9 de julio, Concursal.

62. Por otro lado, la situación de superávit ha supuesto, a efectos de Seguridad Social, y a partir del 1 de julio de 2006, la reducción del tipo de cotización por el FOGASA, a cargo exclusivo del empresario, del 0,40\% al 0,20\% (artículo 11 del Real Decreto-ley 5/2006 y de la Ley 43/2006, por el que se modifica la Ley 30/2005, de 29 de diciembre, de Presupuestos Generales del Estado para el año 2006).

Ello no obstante, resulta patente la incertidumbre que rodea a esta medida, pues según la Disposición Adicional cuarta del Real Decreto-ley 5/2006 y de la Ley $43 / 2006 .$.

«las modificaciones futuras del tipo de cotización y en la cuantía de las prestaciones del FOGASA estarán determinadas por la situación de su excedente financiero, que podrá utilizarse como fondo de estabilización para la financiación de las necesidades anuales del organismo, todo ello previa consulta a su Consejo Rector».

63. En último lugar, conforme a la Disposición Transitoria cuarta del Real Decreto-ley 5/2006 y de la Ley 43/2006, las prestaciones del FOGASA, que correspondan conforme a la nueva redacción del artículo 33 del TRLET, son aplicables a las solicitudes de prestaciones que se hayan presentado a partir del 15 de junio de 2006 (fecha de entrada en vigor del Real Decretoley 5/2006), con independencia de que la declaración de insolvencia empresarial se haya producido con anterioridad.

\subsection{La mejora de la protección por desempleo de colectivos específicos}

64. Este ámbito se caracteriza, principalmente, por el recorte llevado a cabo en el Real Decreto-ley 5/2006 y en la Ley 43/2006, en comparación con las medidas recogidas en el Acuerdo para la mejora del crecimiento y del empleo, de 9 de mayo de 2006.

65. En concreto, el Real Decreto-ley 5/2006 y la Ley 43/2006 no han regulado algunas medidas que sí se contenían en el mencionado acuerdo. Nos referimos a las relativas a los trabajadores del régimen agra- 
rio $^{99}$, a la Renta Activa de Inserción ${ }^{100}$, y a algunas relacionadas con los trabajadores fijos discontinuos ${ }^{101}$.

66. Por el contrario, el Real Decreto-ley 5/2006 y la Ley 43/2006 sí han contemplado el resto de las medidas incluidas en el Acuerdo para la mejora del crecimiento y del empleo, de 9 de mayo de 2006, en relación con la mejora de la prestación por desempleo.

En consecuencia, se han modificado algunos aspectos del TRLGSS para mejorar las situaciones de determinados colectivos. Conforme a la Disposición Final cuarta del Real Decreto-ley 5/2006, las medidas adoptadas se tendrán en cuenta a partir del 1 de julio de 2006.

67. Así, los colectivos afectados por la reforma son los tres siguientes: trabajadores desempleados mayores de 45 años sin cargas familiares; trabajadores fijos discontinuos; y socios trabajadores de cooperativas de trabajo asociado.

68. En lo que respecta a los trabajadores desempleados mayores de 45 años sin cargas familiares, la reforma ha supuesto que podrán valerse del subsidio por desempleo, independientemente de la duración de la prestación por desempleo contributiva que hubieran agotado previamente. Con ante-

${ }^{99}$ En el Acuerdo para la mejora del crecimiento y del empleo, de 9 de mayo de 2006, el Gobierno se comprometía a adoptar «las normas o actuaciones que sean necesarias para la mejora del sistema de protección por desempleo de los trabajadores agrarios».

${ }^{100}$ Conforme al Acuerdo para la mejora del crecimiento y del empleo, de 9 de mayo de 2006, tras la reforma debía considerarse la Renta Activa de Inserción (RAI) «como un derecho subjetivo», y también debía cotizarse a la Seguridad Social por este colectivo. A tal fin, debía aprobarse un Real Decreto de regulación de la RAI, configurándola con carácter permanente en lugar de anual, y previéndose que la entidad gestora debería cotizar durante los once meses de duración de la RAI en las mismas condiciones que en el subsidio por desempleo, es decir, por las contingencias de asistencia sanitaria y protección a la familia.

${ }^{101}$ El Acuerdo para la mejora del crecimiento y del empleo, de 9 de mayo de 2006, recogía una medida según la cual se permitiría al trabajador fijo discontinuo, que no hubiera extinguido el derecho a una prestación por desempleo anterior, optar por reanudar ese derecho o por percibir uno nuevo, siempre que acreditase nuevos períodos de ocupación cotizada de al menos 360 días, así como el cumplimiento de los requisitos exigidos.

Además, se entendía que cuando el trabajador fijo discontinuo optase por reanudar el derecho suspendido, las cotizaciones tenidas en cuenta para la prestación por la que no hubiese optado deberían computarse para el reconocimiento de un derecho posterior.

Por último, y con dudosa legalidad, se establecía que el Servicio Público de Empleo Estatal debía adoptar la instrucciones precisas al respecto. Ciertamente, se habilitaba a este organismo para dar cumplimiento a una medida que supone una excepción a lo actualmente regulado en el artículo 210.3 del Real Decreto Legislativo 1/1994, de 20 de junio, por el que se aprueba el Texto Refundido de la Ley General de la Seguridad Social (TRLGSS) (BOE de 29 de junio de 1994, núm. 154). 
rioridad, sin embargo, este colectivo debía agotar un derecho a prestación por desempleo de, al menos, trescientos sesenta días de duración [el artículo $15 . d o s$ del Real Decreto-ley 5/2006 y de la Ley 43/2006 ha modificado el artículo 215.1.1.b del TRLGSS].

69. Con el objetivo de aclarar las dudas surgidas en torno a los contratos fijos discontinuos y fijos periódicos ${ }^{102}$, y de igualar las condiciones en cuanto a la prestación por desempleo de los trabajadores que prestan sus servicios con uno u otro contrato, el Real Decreto-ley 5/2006 y la Ley 43/2006 establecen en su artículo 15.uno, por el que se modifica el artículo 208.1.4 del TRLGSS, que...

«... se encontrarán en situación legal de desempleo los trabajadores fijos discontinuos, incluidos los que realicen trabajos fijos y periódicos que se repitan en fechas ciertas, en los períodos de inactividad productiva».

Con igual propósito, se recalca, en el mismo precepto, como...

«Las referencias a los fijos discontinuos del título III... [del TRLGSS] y de su normativa de desarrollo incluyen también a los trabajadores que realicen trabajos fijos y periódicos que se repitan en fechas ciertas».

70. Igualmente, el artículo 15.tres Real Decreto-ley 5/2006 y de la Ley 43/2006 ha supuesto la inclusión del colectivo de fijos discontinuos, incluidos los fijos periódicos, entre los beneficiarios del subsidio de desempleo para mayores de 45 años, al que se refiere el artículo 215.1.4 del TRLGSS. Además, respecto a este colectivo se han flexibilizado algunos de los requisitos exigidos con carácter general.

Así pues, los fijos discontinuos, y fijos periódicos, deberán cumplir los siguientes requisitos, para poder acceder al subsidio por desempleo para mayores de 45 años:

- Haber agotado un derecho a la prestación por desempleo de cualquier duración. En cambio, la norma general exige que la prestación contributiva anterior sea de al menos 720 días de duración.

- Ser mayores de 45 años en el momento de la solicitud.

- Haber cotizado como fijos discontinuos un mínimo de nueve años a lo largo de la vida laboral.

${ }^{102}$ En la práctica, las dudas encontraban su razón de ser en la distinta regulación que de estas modalidades contractuales se realiza en el TRLET. Así, al referirse el TRLGSS únicamente a los fijos discontinuos, cabía la posibilidad de entender, literalmente, que la protección otorgada por esta norma se dirigía solamente a los sujetos con contratos de trabajo fijos discontinuos, según el artículo 15.8 del TRLET, y no a los trabajadores con contratos de trabajo fijo periódicos, según el articulo 12.3 del TRLET. 
- Cumplir todos los requisitos para el subsidio por desempleo, menos el del período de espera de un mes.

- No haber generado derecho a una nueva prestación de nivel contributivo o no tener derecho al subsidio previsto para mayores de 52 años.

71. Finalmente, el artículo 16 del Real Decreto-ley 5/2006 y de la Ley $43 / 2006$ reconoce a los socios trabajadores de cooperativas de trabajo asociado el derecho a la situación legal de desempleo tras la extinción de su vínculo societario temporal con la cooperativa.

Con este reconocimiento se modifican los artículos 2, 3 y 5 del Real Decreto 1043/1985, de 19 de junio, por el que se amplía la protección por desempleo a los socios trabajadores de cooperativas de trabajo asociado ${ }^{103}$.

En definitiva, la reforma supone la mejora de la regulación de la prestación por desempleo de este colectivo, puesto que se añade una nueva causa de situación legal de desempleo, teniendo en cuenta que con anterioridad no se reconocía el derecho de desempleo de los socios temporales. De este modo, se pretende equiparar la situación de los socios trabajadores temporales con la situación de los trabajadores con contrato de trabajo temporal.

72. Al margen de estos colectivos, la Ley 43/2006, especialmente preocupada por las personas con discapacidad, prevé en su Disposición Adicional duodécima la creación de la Estrategia Global de Empleo para personas con discapacidad 2007-2008.

Esta estrategia deberá ser aprobada por el Gobierno en el plazo de seis meses desde la entrada en vigor de la Ley 43/2006 (a saber, el 31 de diciembre de 2006), tras consultar a los interlocutores sociales y a las organizaciones representativas de personas con discapacidad y a sus familias.

La estrategia contendrá un repertorio, con su correspondiente calendario de iniciativas y medidas normativas, programáticas y presupuestarias, dirigidas a promover el acceso de las personas con discapacidad al mercado de trabajo, mejorando su empleabilidad y su integración laboral. Además, los principales objetivos de la estrategia consistirán en disminuir los índices de desempleo y elevar las tasas de actividad de las personas con discapacidad, con especial atención a las mujeres con discapacidad, y aquellas otras personas que por su discapacidad presentan dificultades severas de acceso al mercado de trabajo.

\subsection{La mejora de los servicios públicos en el mercado de trabajo}

73. En realidad, más que de mejoras de los servicios públicos en el mercado cabe hablar de medidas programáticas, o de futuro, sin concreción alguna.

${ }^{103}$ BOE de 2 de julio de 1985, núm. 157. 
74. Según se deduce del Real Decreto-ley 5/2006 y de la Ley 43/2006, básicamente, estas medidas afectarán a la Inspección de Trabajo y Seguridad Social (ITSS) y a los Servicios Públicos de Empleo (SPE).

75. En lo que se refiere a la ITSS, se pretende fomentar la participación de las organizaciones sindicales y empresariales más representativas para determinar los objetivos y programas del sistema de ITSS, en el ámbito de la Administración General del Estado y de las comunidades autónomas.

Para ello, se prevé la creación de órganos de representación de carácter consultivo de composición tripartita y paritaria, a través de los cuales las organizaciones sindicales y empresariales más representativas podrán ser consultadas y podrán formular sus propuestas.

Es más, en el Real Decreto-ley 5/2006, el Gobierno se comprometía a que el Ministerio de Trabajo y Asuntos Sociales dictase, en el plazo de tres meses, las normas oportunas para la constitución del órgano correspondiente en el ámbito de la Administración General del Estado (Disposición Final primera). Dicho plazo, se entiende que empezaba a contar tras la entrada en vigor del Real Decreto-ley 5/2006, es decir, tras el 15 de junio de 2006. Ahora, es la Ley 43/2006 la que vuelve establecer un plazo de tres meses (Disposición Final primera), que, se entiende, contará a partir de la entrada en vigor de dicha ley, el 31 de diciembre de 2006.

Como es lógico, respecto a los órganos que deban constituirse en las comunidades autónomas para que las organizaciones sindicales y empresariales más representativas puedan participar, el Gobierno ha respetado la capacidad de autoorganización de las comunidades autónomas. En este sentido, llama la atención cómo la reforma, que no ha tenido en cuenta, en su gestación, ni a las comunidades autónomas, ni a los sindicatos y asociaciones de empresarios con mayor representatividad de éstas, los considera imprescindibles a la hora de materializar sus objetivos en materia de inspección de trabajo y de la Seguridad Social.

Pero, también en este ámbito, se ha optado por no recoger en el Real Decreto-ley 5/2006 y en la Ley 43/2006 ciertos aspectos que sí se contemplaban en el Acuerdo para la mejora del crecimiento y del empleo, de 9 de mayo de 2006. Nos referimos concretamente a las medidas relativas al reforzamiento de los efectivos y medios técnicos y materiales del ITSS, así como a la planificación y programación de las campañas específicas en la actuación de la ITSS, sobre todo en las de carácter informativo y de promoción y divulgación de la normativa laboral. Igualmente, en el Acuerdo se señalaban, al margen del clásico campo de la prevención de los riesgos laborales, los siguientes campos en los que se pretende potenciar la intervención de la ITSS: a) revisión del fraude en la contratación temporal en empresas o sectores con una tasa de temporalidad superior a la media; b) igualdad de trato y no discriminación; c) empleo irregular: inmigrantes y economía sumergida; d) empleo de personas con discapacidad. 
76. Por otro lado, ante la falta de coordinación adecuada entre el SPE Estatal y los correspondientes Servicios Públicos de Empleo de las comunidades autónomas, el Gobierno deberá instrumentar, en un plazo de tres meses desde la entrada en vigor de la Ley 43/2006, es decir, a partir del 31 de diciembre de 2006, un Plan Global de Modernización del Servicio Público de Empleo Estatal, con la finalidad de garantizar la adecuada coordinación con los Servicios Públicos de Empleo autonómicos, y de modernizar y mejorar los recursos materiales y tecnológicos de la red de oficinas. Dicho plan deberá incluir, además, un Plan Estratégico de Recursos Humanos del Servicio Público de Empleo Estatal para mejorar su estructura organizativa y la situación laboral y retributiva de su personal (Disposición Adicional sexta de la Ley 43/2006) (104. $^{104}$.

Tal y como se desprende del Acuerdo para la mejora del crecimiento y del empleo, de 9 de mayo de 2006, el objetivo del Plan Global de Modernización es el siguiente:

«mejorar la atención a los usuarios y la calidad de los servicios, garantizando la coordinación entre políticas activas y protección por desempleo y elevando la tasa de intermediación en el mercado laboral de los Servicios Públicos de Empleo».

Igualmente, como novedad, y fuera de lo estrictamente contemplado en el Acuerdo para la mejora del crecimiento y del empleo, de 9 de mayo de 2006, se atribuye a la Fundación Tripartita para la Formación en el Empleo la función de actuar como entidad colaboradora y de apoyo técnico del SPE Estatal, en el marco del Sistema de Formación Profesional, en los términos que se establezcan reglamentariamente (Disposición Adicional quinta del Real Decreto-ley 5/2006 y de la Ley 43/2006).

En cambio, no se han incorporado al Real Decreto-ley 5/2006 ni a la Ley 43/2006 algunos de los compromisos adoptados en el Acuerdo para la mejora del crecimiento y del empleo, de 9 de mayo de 2006.

Así, en primer lugar, aunque de manera genérica y abstracta, el Gobierno y los interlocutores sociales del Acuerdo adoptaron el compromiso de evaluar durante el segundo semestre del 2006 el funcionamiento de las medidas que configuran el conjunto de las políticas activas de empleo. Asimismo, en este mismo ámbito, el Gobierno aseguraba el cumplimiento del objetivo según el cual los demandantes de empleo deben recibir una oferta de orientación, formación profesional e inserción laboral, en un plazo no superior a seis meses desde su inscripción en la Oficina de Empleo.

En segundo lugar, en el Acuerdo se anunciaba la creación de un grupo de trabajo tripartito en el ámbito del SPE Estatal, con el objetivo de abordar

${ }^{104}$ Esta medida también se contemplaba en la Disposición Adicional sexta del Real Decreto-ley 5/2006. 
el desarrollo de la Ley 56/2003, de 16 de diciembre, de Empleo ${ }^{105}$ y las políticas activas de empleo que deben aplicarse en el futuro, con especial atención a mujeres, jóvenes y personas con discapacidad, así como las medidas de empleo y formación a favor de la integración laboral de la población inmigrante. Por otro lado, se hacía hincapié en el análisis del papel de los agentes que intervienen en el mercado de trabajo y su ámbito de actuación, a saber, los Servicios Públicos de Empleo, las Entidades Colaboradoras, las Agencias de Colocación y las Empresas de Recolocación.

En este ámbito, en cambio, se echa en falta la participación en el grupo de trabajo de las comunidades autónomas y de los sindicatos y asociaciones de empresarios con mayor representatividad en ellas.

${ }^{105}$ BOE de 17 de diciembre de 2003, núm. 301. 
ANEXO. Programa de Fomento de Empleo de la Ley 43/2006 (Incentivos empresariales a la contratación laboral)

\begin{tabular}{|c|c|c|c|}
\hline Colectivos & Descripción & $\begin{array}{c}\text { Cuantía anual } \\
\text { (en euros) }\end{array}$ & Duración \\
\hline
\end{tabular}

Incentivos a la contratación indefinida inicial

\begin{tabular}{|l|l|l|l|}
\hline \multirow{5}{*}{ Mujeres } & $\begin{array}{l}\text { Desempleadas, así como las víc- } \\
\text { timas de violencia de género o } \\
\text { de violencia doméstica [art. } \\
\text { 2.1.a y 2.4] }\end{array}$ & 4 850 \\
\cline { 2 - 2 } & $\begin{array}{l}\text { Contratadas en los 24 meses } \\
\text { siguientes al parto, a la adopción } \\
\text { o al acogimiento tanto preadop- } \\
\text { tivo como permanente [art. } \\
\text { 2.1.b] }\end{array}$ & \multirow{2}{*}{1200} & 4 años \\
\cline { 1 - 2 } & $\begin{array}{l}\text { Contratadas después de 5 años } \\
\text { de inactividad laboral, si, an- } \\
\text { teriormente a su retirada, han } \\
\text { trabajado, al menos, 3 años } \\
\text { [art. 2.1.c] }\end{array}$ & \\
\hline
\end{tabular}

\begin{tabular}{|l|c|l|}
\hline Mayores de 45 años [art. 2.1.d] & 1200 & $\begin{array}{l}\text { Toda la } \\
\text { vigencia del } \\
\text { contrato }\end{array}$ \\
\hline
\end{tabular}

\begin{tabular}{|l|l|l|l|}
\hline Jóvenes & De 16 a 30 años [art. 2.1.c] & 800 & 4 años \\
\hline
\end{tabular}

\begin{tabular}{|c|c|c|c|}
\hline \multirow{2}{*}{$\begin{array}{l}\text { Otros } \\
\text { colectivos y } \\
\text { situaciones } \\
\text { especiales }\end{array}$} & $\begin{array}{l}\text { Parados de al menos } 6 \text { meses y } \\
\text { trabajadores en situación de } \\
\text { exclusión social [arts. 2.1.f y } \\
2.5 \text { ] }\end{array}$ & 600 & 4 años \\
\hline & $\begin{array}{l}\text { Personas con discapacidad } \\
\text { genérica (art. 2.2.1) }\end{array}$ & 4500 & $\begin{array}{l}\text { Toda la } \\
\text { vigencia del } \\
\text { contrato }\end{array}$ \\
\hline
\end{tabular}

${ }^{106} \mathrm{Si}$ el trabajador con discapacidad tiene en el momento de la contratación 45 o más años o si se trata de una mujer, la subvención se incrementará, respectivamente, en 1200 euros al año o en 850 euros al año, sin que estos incrementos sean compatibles entre sí (art. 2.2.3). 


\begin{tabular}{|c|c|c|c|}
\hline \multirow[t]{2}{*}{$\begin{array}{l}\text { Otros } \\
\text { colectivos y } \\
\text { situaciones } \\
\text { especiales }\end{array}$} & 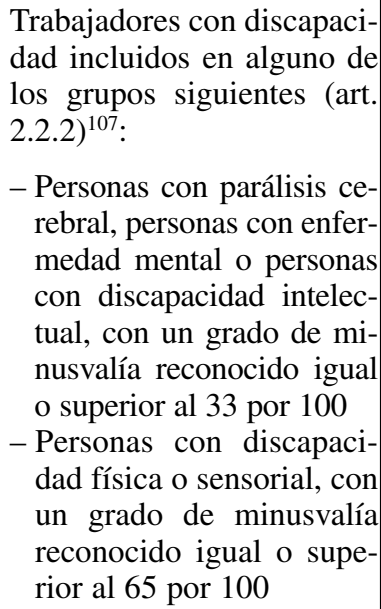 & 5100 & $\begin{array}{l}\text { Toda la } \\
\text { vigencia del } \\
\text { contrato }\end{array}$ \\
\hline & $\begin{array}{l}\text { Trabajadores con discapa- } \\
\text { cidad contratados por un } \\
\text { centro especial de empleo } \\
(\text { art. 2.3) }\end{array}$ & $\begin{array}{l}\text { Bonificaciones del } \\
100 \text { por } 100 \text { de la } \\
\text { cuota empresarial a la } \\
\text { Seguridad Social, in- } \\
\text { cluidas las de acci- } \\
\text { dentes de trabajo y } \\
\text { enfermedad profesio- } \\
\text { nal y las cuotas de } \\
\text { recaudación conjunta }\end{array}$ & $\begin{array}{l}\text { Toda la } \\
\text { vigencia del } \\
\text { contrato }\end{array}$ \\
\hline
\end{tabular}

${ }^{107} \mathrm{Si}$ el trabajador con discapacidad tiene en el momento de la contratación 45 o más años o si se trata de una mujer, la subvención se incrementará, respectivamente, en 1200 euros al año o en 850 euros al año, sin que estos incrementos sean compatibles entre sí (art. 2.2.3).

${ }^{108} \mathrm{Si}$ bien las relaciones laborales de carácter especial se excluyen del Programa de Fomento del empleo, la Ley 43/2006, en el artículo 6.1.a, modifica lo establecido por el Real Decreto-ley 5/2006 y deja al margen de dicha exclusión la relación laboral de trabajadores con discapacidad en centro especial de empleo. En este sentido, es la propia Ley 43/2006 la que establece el sistema de bonificaciones mediante porcentajes de las cotizaciones sociales por la contratación de personas con discapacidad por los centros especiales de empleo. En principio, este sistema debe comenzar a aplicarse desde la entrada en vigor de la Ley 43/2006, es decir, desde el 31 de diciembre de 2006, y se mantendrá en vigor hasta tanto no se adopte otra decisión por parte del Gobierno y las organizaciones sindicales y empresariales más representativas, incluidas las organizaciones del sector de la discapacidad, quienes evaluarán el funcionamiento de las medidas que configuran el conjunto de las políticas de empleo de las personas con discapacidad, con la finalidad de determinar las políticas activas de empleo que se aplicarán en el futuro. Igualmente, el Consejo Nacional de la Discapacidad deberá emitir un informe al respecto (Disposición Final cuarta de la Ley 43/2006). No obstante, por motivos transitorios, tales bonificaciones podrán aplicarse entre el 1 de julio de 2006 y la fecha de entrada en vigor de la Ley 43/2006, para lo que la Tesorería General de la Seguridad Social impulsará de oficio la devolución de las diferencias en las cuotas correspondientes a los períodos ya ingresados (Disposición Transitoria primera de la Ley 43/2006). 


\begin{tabular}{|c|c|c|c|}
\hline \multirow{3}{*}{$\begin{array}{l}\text { Otros } \\
\text { colectivos y } \\
\text { situaciones } \\
\text { especiales }\end{array}$} & $\begin{array}{l}\text { Transformaciones en inde- } \\
\text { finidos de contratos tem- } \\
\text { porales de fomento del em- } \\
\text { pleo celebrados con perso- } \\
\text { nas con discapacidad, o de } \\
\text { contratos formativos suscri- } \\
\text { tos con trabajadores con } \\
\text { discapacidad (art. 2.2.1) }\end{array}$ & 4500 & $\begin{array}{l}\text { Toda la } \\
\text { vigencia del } \\
\text { contrato }\end{array}$ \\
\hline & $\begin{array}{l}\text { Transformaciones en inde- } \\
\text { finidos: de contratos tem- } \\
\text { porales de fomento del } \\
\text { empleo celebrados por un } \\
\text { centro especial de empleo } \\
\text { con personas con discapa- } \\
\text { cidad, o de contratos for- } \\
\text { mativos suscritos por un } \\
\text { centro especial de empleo } \\
\text { con trabajadores con disca- } \\
\text { pacidad (art. } 2.3 \text { ) }\end{array}$ & $\begin{array}{l}\text { Bonificaciones del } \\
100 \text { por } 100 \text { de la } \\
\text { cuota empresarial a la } \\
\text { Seguridad Social, } \\
\text { incluidas las de acci- } \\
\text { dentes de trabajo y } \\
\text { enfermedad profesio- } \\
\text { nal y las cuotas de } \\
\text { recaudación conjunta }\end{array}$ & $\begin{array}{l}\text { Toda la } \\
\text { vigencia del } \\
\text { contrato }\end{array}$ \\
\hline & $\begin{array}{l}\text { Transformaciones en inde- } \\
\text { finidos de contratos forma- } \\
\text { tivos, de relevo y sustitu- } \\
\text { ción por jubilación (art. } \\
\text { 2.6) }\end{array}$ & 500 & 4 años \\
\hline
\end{tabular}

\section{Plan Extraordinario para la Conversión de Empleo Temporal en Fijo}

Transformaciones en indefinidos de contratos temporales, incluidos los contratos formativos, de relevo y de sustitución por jubilación, en todos los casos celebrados antes del 1 de julio de 2006, siempre que la transformación se realice antes del 1 de enero de 2007 (art. 3)

Subvenciones en supuestos excepcionales de contratación temporal

\begin{tabular}{|l|l|l|}
$\begin{array}{l}\text { Personas con discapacidad contratadas mediante } \\
\text { contrato temporal de fomento del empleo (art. } \\
2.2 .4)^{109}\end{array}$ & 3500 & $\begin{array}{l}\text { Toda la } \\
\text { vigencia del } \\
\text { contrato }\end{array}$ \\
\hline
\end{tabular}

${ }^{109} \mathrm{Si}$ el trabajador con discapacidad tiene en el momento de la contratación 45 o más años o si se trata de una mujer, la subvención se incrementará en ambos supuestos en 600 euros al año; tales incrementos son compatibles entre sí (art. 2.2.4). 


\begin{tabular}{|c|c|c|}
\hline $\begin{array}{l}\text { Trabajadores con discapacidad incluidos en } \\
\text { alguno de los grupos siguientes (art. } 2.2 .4)^{110} \text { : } \\
\text { - Personas con parálisis cerebral, personas } \\
\text { con enfermedad mental o personas con dis- } \\
\text { capacidad intelectual, con un grado de } \\
\text { minusvalía reconocido igual o superior al } \\
33 \text { por } 100 \\
\text { - Personas con discapacidad física o sen- } \\
\text { sorial, con un grado de minusvalía recono- } \\
\text { cido igual o superior al } 65 \text { por } 100\end{array}$ & 4100 & $\begin{array}{l}\text { Toda la } \\
\text { vigencia del } \\
\text { contrato }\end{array}$ \\
\hline $\begin{array}{l}\text { Trabajadores con discapacidad contratados } \\
\text { por un centro especial de empleo (art. 2.3) }\end{array}$ & $\begin{array}{l}\text { Bonificaciones del } \\
100 \text { por } 100 \text { de la } \\
\text { cuota empresarial a la } \\
\text { Seguridad Social, in- } \\
\text { cluidas las de acci- } \\
\text { dentes de trabajo y } \\
\text { enfermedad profesio- } \\
\text { nal y las cuotas de } \\
\text { recaudación conjunta }\end{array}$ & $\begin{array}{l}\text { Toda la } \\
\text { vigencia del } \\
\text { contrato }\end{array}$ \\
\hline $\begin{array}{l}\text { Víctimas de violencia de género o domésti- } \\
\text { ca (art. 2.4) }\end{array}$ & 600 & $\begin{array}{l}\text { Toda la } \\
\text { vigencia del } \\
\text { contrato }\end{array}$ \\
\hline $\begin{array}{l}\text { Personas en situación de exclusión social } \\
\text { (art. 2.5) }\end{array}$ & 500 & $\begin{array}{l}\text { Toda la } \\
\text { vigencia del } \\
\text { contrato }\end{array}$ \\
\hline
\end{tabular}

\section{Bonificaciones y subvenciones para el mantenimiento del empleo indefinido}

Contratos de carácter indefinido de trabajadores de 60 o más años con una antigüedad en la empresa de 5 o más años (art. 4.1)
El 50 por 100 de la aportación empresarial por contingencias comunes salvo inca- Toda la pacidad temporal, in- vigencia del c r e mentánd o s e contrato anualmente un 10 por 100, hasta el 100 por 100

${ }^{110} \mathrm{Si}$ el trabajador con discapacidad tiene en el momento de la contratación 45 o más años o si se trata de una mujer, la subvención se incrementará en ambos supuestos en 600 euros al año, siendo tales incrementos compatibles entre sí (art. 2.2.4). 


\begin{tabular}{|c|c|c|}
\hline $\begin{array}{l}\text { Mujeres con contrato suspendido (indefinido } \\
\text { o temporal que se transforme en indefinido) } \\
\text { reincorporadas en el plazo de } 2 \text { años desde } \\
\text { el inicio del permiso de maternidad, siempre } \\
\text { que esta reincorporación sea a partir del } 1 \\
\text { de julio de } 2006 \text { (art. } 4.2 \text { ) }\end{array}$ & 1200 & 4 años \\
\hline
\end{tabular}

